\title{
Opposed Jet Burner Approach for Characterizing Flameholding Potentials of Hydrocarbon Scramjet Fuels
}

\author{
Gerald L. Pellett ${ }^{*}$, Janet L. Convery ${ }^{2}$, and Lloyd G. Wilson ${ }^{3}$
}

\begin{abstract}
Opposed Jet Burner (OJB) tools have been used extensively by the authors to measure Flame Strength (FS) extinction limits of laminar $\mathrm{H}_{2} / \mathrm{N}_{2}$-air and (recently) hydrocarbon (HC)-air Counterflow Diffusion Flames (CFDFs) at one atm. This paper details normalization of FSs of $\mathrm{N}_{2}$ diluted $\mathrm{H}_{2}$ and $\mathrm{HC}$ systems to account for effects of fuel composition, temperature, pressure, jet diameter, inflow Reynolds number, and inflow velocity profile (plug, contoured nozzle; and parabolic, straight tube). Normalized results exemplify a sensitive accurate means of validating, globally, reduced chemical kinetic models at $\sim 1$ atm and the relatively low temperatures approximating the loss of non-premixed "idealized" flameholding, e.g., in scramjet combustors.

Laminar FS is defined locally as maximum air input velocity, $U_{\text {air, }}$, that sustains combustion of a counter-jet of g-fuel at extinction. It uniquely characterizes a fuel. And global axial strain rate at extinction $\left(U_{\text {air }}\right.$ normalized by nozzle or tube diameter, $\left.D_{\mathrm{n} \text { or }}\right)$ can be compared directly with computed extinction limits, determined using either a 1-D Navier Stokes stream-function solution, using detailed transport and finite rate chemistry, or (better yet) a detailed 2-D Navier Stokes numerical simulation. The experimental results define an "idealized flameholding reactivity scale" that shows wide ranging $(50 \mathrm{x})$ normalized FS's for various vaporized-liquid and gaseous HCs, including, in ascending order: JP-10, methane, JP-7, $n$-heptane, $n$-butane, propane, ethane, and ethylene. Results from $\mathrm{H}_{2}$-air produce a unique and exceptionally strong flame that agree within $\sim 1 \%$ of a recent 2-D numerically simulated FS for a $3 \mathrm{~mm}$ tube-OJB. Thus we suggest that experimental FS's and/or FS ratios, for various neat and blended HCs w/ and w/o additives, offer accurate global tests of chemical kinetic models at the Ts and Ps of extinction.

In conclusion, we argue the FS approach is more direct and fundamental, for assessing, e.g., idealized scramjet flameholding potentials, than measurements of laminar burning velocity or blowout in a Perfectly Stirred Reactor, because the latter characterize premixed combustion in the absence of aerodynamic strain. And FS directly measures a chemical kinetic characteristic of non-premixed combustion at typical flameholding temperatures. It mimics conditions where gfuels are typically injected into a subsonic flameholding recirculation zone that captures air, where the effects of aerodynamic strain and associated multi-component diffusion become important.

\footnotetext{
* Senior Research Scientist, Hypersonic Air Breathing Propulsion Branch, Research and Technology Directorate. MS 168, NASA Langley Research Center, Hampton, VA 23681. Senior Member, AIAAｇ.l.pellett@larc.nasa.gov

${ }^{2}$ Graduate Student, National Institute of Aerospace, Hampton, VA; and Mechanical Engineering Department, VPI \& SU, Blacksburg, VA; Member AIAA

${ }^{3}$ Technician, Lockheed Martin Space Operations, Hampton, VA
}

This material is declared a work of the U.S Government and is not subject to copyright protection in the United States.

Approved for public release; distribution is unlimited. 


\section{Introduction}

For over 40 years, liquid hydrogen fuel has been used almost exclusively in studies aimed at realizing the potential of airbreathing Supersonic Combustion Ramjet (SCRAMJET) propulsion. Although liquid hydrogen is very difficult (and expensive) to use, it has remained the fuel of "choice," largely because of gaseous hydrogen's exceptional reactivity at near-atmospheric pressures, and to a lesser extent, its high specific impulse and unique capacity for active cooling. Liquid hydrocarbon $(\mathrm{HC})$ fuels, on the other hand, have not been very useful for supersonic airbreathing applications because they are far less reactive, although they are obviously much easier to store and handle. Recently, endothermic catalytic cracking of $\mathrm{HC}$ fuels has also been investigated [1-2]. Difficult and competing objectives remain, however, to achieve ignition and robust combustion in relatively small subsonic cavity flameholders - so as to (a) generate rapid reaction with sufficient initial heat release, (b) avoid excessive internal drag and loss of net thrust, and (c) achieve needed "endothermic" heat soak in active cooling channels without the formation and deposition of significant carbon residues [2-8]. Thus catalytically cracked fuel vapor and entrained air must mix, diffuse and react long enough in a subsonic cavity to achieve ignition with robust "incipient flameholding," to supply radicals and adequate enthalpy to the overriding supersonic flow, with minimal loss of initial kinetic energy.

Opposed Jet Burner (OJB) tools have been used extensively by the authors to measure "Flame Strengths" at extinction of numerous laminar fuel-air Counterflow Diffusion Flames (CFDFs) at one atmosphere [9-20]. Early efforts focused on the velocity and thermal structure, and strain-induced extinction of 14 to $100 \%$ hydrogen-air CFDFs, summarized in [9]; the use of silane/hydrogen and silane/hydrocarbon mixtures for piloting very high speed combustion [10$11,16]$; and the effects of vitiated air contaminants from test facilities on "incipient flameholding" in subsonic recirculating flows of an otherwise supersonic combustor [12-15,17,21,22]. These studies have shown that Flame Strength, FS, defined locally as the maximum air input velocity, $U_{\text {air }}$, which sustains combustion of a counterflowing jet of gaseous fuel just before extinction, represents a unique and important fuel-characterization parameter for "idealized" scramjet flameholding $[21,22,9]$. And, measurements of global axial strain rate, or Applied Stress Rate (ASR) at extinction (proportional to $U_{\text {air }}$ normalized by either nozzle or tube diameter, $D_{\mathrm{n}}$ or $\mathrm{t}$ ), can be compared directly with numerically simulated laminar extinction limits $[18,19,9,23]$. Such limits may be evaluated quite accurately using either a 1-D Navier Stokes stream-function approximation [20] with detailed transport and finite rate chemistry, or a fully detailed 2-D Navier Stokes numerical simulation [23].

This paper presents comprehensive data sets and analyses that represent an idealized Flame Strength (FS) approach to the assessment of so-called incipient flameholding limits in practical $\mathrm{HC}$-air systems, near atmospheric pressure. It builds upon recent gaseous- and vaporized-HC FS results that were first presented [24] during the middle-phase of a MS study. Subsequently, that study included additional vaporized $\mathrm{HC}$ data, and details of normalizing vaporization and OJB extinction data to account for the effects of input temperature, pressure and jet diameter, and inflow Reynolds number and velocity profile (plug vs parabolic inflows) [25]. The present paper extends the [25] study by including additional $\mathrm{HC}$-air and supporting $\mathrm{H}_{2}$-air extinction data, and refined assessments of OJB strain rates from nozzle- and tube-OJBs to define better the effects of jet diameter, inflow velocity profile, Reynolds number, and fuel composition. The expanded sets of extinction data also help provide a more accurate and comprehensive means of globally validating reduced chemical kinetic models for $\mathrm{HCs}$, at temperatures appropriate to strain-induced OJB extinctions and to the loss of non-premixed idealized, incipient flameholding in more complex scramjet combustors. The study concludes with a comprehensive normalization of the nozzle and tube OJB data that characterize steady (and dynamic [26-29]) strain-induced extinction of a very wide range of non-premixed fuel-air systems, near atmospheric pressure. 


\section{Experimental}

Schematics of a typical nozzle-OJB (and Oscillatory-inflow nozzle-OJB) system, Fig 1a, and the most recent tube-OJB system, Fig. 1b, illustrate the use of convergent Pyrex nozzles, and long Pyrex, nickel or stainless steel tubes (50 to 100 diameters), of the same size and type. No guard flows were used (or seemed to be needed) at the typical flow rates employed for extinction of flat disk-shaped flames; horizontal configurations also favored formation of resultant ringshaped flames and measurements of flame restoration. The ceramic fiberboard boxes each had Pyrex windows, and a porous sintered metal plate over the top. Nitrogen (or argon) entering through diffuser jets at the bottom of each box reduced extraneous combustion outside the central impingement region, and thus minimized adverse buoyancy and visibility effects. Fuel and air component flows were hand-controlled with micrometer valves, and measured by mass flow meters calibrated at $0^{\circ} \mathrm{C}$ and $1 \mathrm{~atm}$.

To attain extinction (Blowoff) of a stabilized $\mathrm{H}_{2} / \mathrm{N}_{2}$-air disk flame, the $\mathrm{H}_{2}$ flow was gradually increased -- or fixed at a target rate as $\mathrm{N}_{2}$ fuel diluent was increased; simultaneously, the airflow was gradually increased, so the flame was always centered and free-floating (fully responsive to small changes in flow rates). Upon sudden Blowoff, a ring flame often stabilized. After mass flows of each component were recorded, gradual flow reductions caused slow closure of the ring flame, and eventually sudden disk Restoration. Extinction data were almost always obtained in duplicate, and were sometimes replicated up to 10 times. The same Blowoff limits of $\mathrm{N}_{2}$-air could be reached by appropriate fixing of $\mathrm{N}_{2}$ flows and decreasing $\mathrm{H}_{2}$ flows. Similar procedures applied to obtaining extinction limits for gaseous $\mathrm{HC} / \mathrm{N}_{2}$-air and mixed $\mathrm{H}_{2} / \mathrm{HC}$-air and $\mathrm{HC}_{1} / \mathrm{HC}_{2}$-air systems, in that $\mathrm{N}_{2}$ or $\mathrm{HC}$ diluent/reactant was increased in tandem with air to achieve extinction. Premixed and diluted vaporized-HC flows were simply varied in tandem with flows of air.

The reported cross-section-average jet velocities, $U_{\text {air }}$ and $U_{\text {fuel }}$, were calculated from component mass flow rates and nozzle or tube exit diameters; these apply at $0{ }^{\circ} \mathrm{C}$ and 1 -atm conditions, unless attributed to $300 \mathrm{~K}$, or higher. Corresponding $R e_{\text {air }}$ were generally less than 1500 , but considerably lower values were avoided, especially because CFDFs can become excessively thick when vertical, and also non-axisymmetric when horizontal, due to buoyancy. Radiation effects were considered negligible at the relatively high strain rates used.

The various tube-OJBs $(1.8,2.70,2.91,4.96,5.0,7.0,7.5$, and $10.0 \mathrm{~mm})$ were mounted horizontally. The brass $5.3 \mathrm{~mm}$ nozzle was mounted horizontally, and the $2.7 \mathrm{~mm}, 5.1 \mathrm{~mm}$ and $7.2 \mathrm{~mm}$ Pyrex nozzle-OJBs were mounted vertically, with each upper element insulated to reduce convective heating of the fuel.

Both the 2.7 and $2.91 \mathrm{~mm} \mathrm{OJB's} \mathrm{were} \mathrm{spaced} 7 \mathrm{~mm}$ apart to ensure a free-floating finitethickness flame, free of significant flame attachment / anchoring effects. The larger tube- and nozzle-OJBs were generally spaced 1.5 to 2 exit diameters apart. Flow rates were generally high enough that buoyancy effects on flame extinction limits appeared negligible (and were, shown later) whenever data were recorded. Vaporized $\mathrm{HC}$ fuel mixtures flowed through electrically heated tubes, with thermocouple monitoring, before entering the OJB combustion chamber, so these fuels were heated up to $500-600 \mathrm{~K}$ to prevent condensation. Systematic checks of propane-air extinction limits using ambient temperature air, and unheated, rapidly-heated ( $5 \mathrm{~min}$ at $600 \mathrm{~K})$, and long-term-heated propane $(\sim 2 \mathrm{hr}$ at $600 \mathrm{~K})$ showed very small difference in FS due to short term $(1.5 \%)$ or long term $(3 \%)$ heating of the fuel.

Errors in extinction limits stemmed from various sources. Because absolute strain rates at extinction were predicted (1-D) to vary linearly with input temperature, up to $\sim 600 \mathrm{~K}[30,31]$, and experimental ASRs using a $2.7 \mathrm{~mm}$ tube-OJB were found to vary "nearly" linearly (e.g., with a 
$14 \%$ excess increase from 300 to $600 \mathrm{~K}$ [32]), direct measurements of mass flow rates effectively negated most effects of variable jet temperature on absolute jet velocity, via the ideal gas law. This led to significant reduction of data scatter with required input heating. Atmospheric pressure variations caused small variations of $U_{\text {air }}$ extinction limits that were ignored (and averaged-out) during most of the hydrogen extinction studies, but more recently the $\mathrm{HC}$ and $\mathrm{H}_{2}$ data were corrected [25] by applying a factor of $(1-\mathrm{atm} / P)^{3}$. Calculated jet exit velocities at standard conditions varied inversely as the square of measured $D$, and thus ASRs varied as $D^{-3}$. Finally, un-reconciled small differences between data sets were due to unmeasured variations in atmospheric pressure (which sometimes averaged-out); differences in centering flames; daily jet realignment; sporadic mass flow meter drift, periodic re-calibrations, and small transient cooling/heating flow response effects in flow meters; and differences in the spatial distribution and flow rates of argon or nitrogen purge flows.

Because jet-edge velocity-mismatch and bath gas entrainment/diffusion effects were incipient and evident at high $\mathrm{H}_{2}$ concentrations with the $2.7 \mathrm{~mm}$ nozzle-OJB [9], and also the flame thickness at extinction was $\sim 1 / 3 D$, the greatest uncertainty and non-ideality in our previous $\mathrm{H}_{2}-$ "clean air" extinction studies [9] is now believed to be associated with the $2.7 \mathrm{~mm}$ nozzle-OJB.

In summary, ideal, robust tube-OJBs (and the $7.2 \mathrm{~mm}$ nozzle-OJB) were the primary tools used for assessing strain-induced extinction limits of $\mathrm{H}_{2} / \mathrm{N}_{2}$-air and various $\mathrm{HC} / \mathrm{N}_{2}$-air CFDFs in the present study.

\section{Results and Discussion}

In this section we present several distinct sets of experimental results that help define key aspects of opposed jet combustion pertinent to the tools used, and the specific results obtained. Our results include the following: (1) A graphical summary of published Laser Doppler Anemometry (LDA) data will show detailed results for opposed cold flows from finite size contoured nozzles $\left(D_{\mathrm{n}}=25 \mathrm{~mm}\right.$ diameter). These will illustrate the effects of nozzle separation on axial and radial strain rates at fixed exit flow rates, and on various strain rate approximations suggested and adopted by two reseachers. One of these will exhibit a significant departure from measured strain rates when the nozzles are closely spaced $\left(H / D_{\mathrm{n}} \ll 1\right)$. (2) A series of OJB extinction and flame restoration results will be shown for $\mathrm{N}_{2}$-diluted $\mathrm{H}_{2}$ vs air CFDFs using tubeOJBs. These will illustrate significant effects of $\mathrm{H}_{2}$ concentration and tube diameter, $D_{\mathrm{t}}$, on the Flame Strength ( $\mathrm{FS}=U_{\text {air }}$ ) extinction limit, and the insensitivity of $\mathrm{FS}$ to tube spacing and tube orientation, e.g., two vertical and one horizontal. And these $\mathrm{H}_{2}$-air FS results will be followed by an empirical fit of Applied Stress Rate $\left(A S R=U_{\text {air }} / D_{\mathrm{t}}\right)$ for all the FS data, for a wide range of tube diameters $(1.8-10 \mathrm{~mm})$ and $\mathrm{H}_{2}$ concentrations $(20-100 \%)$, for later comparisons with $\mathrm{HC}$-air ASR extinction data. (3) A series of extinction results will be shown for $\mathrm{N}_{2}$-diluted-and $100 \%$ methane-air; these were derived from $7 \mathrm{~mm}$ tube-OJBs with vertical and horizontal orientations, and with fixed and variable tube-OJB spacing. (4) Two plots of ASRs will be shown for all the simple gaseous $\mathrm{HC}$-air systems studied (five), and nearly all the OJB tube sizes used (7 sets, 2.7 $-10 \mathrm{~mm}$ ). These will illustrate asymptotic approaches towards effectively constant ASR extinction limits for each fuel, as tube diameter increases relative to flame thickness, and as exit Reynolds number increases. (5) A series of $\mathrm{HC}$-air extinction results will be shown, including pure and $\mathrm{N}_{2}$-diluted methane and propane vs air from an early horizontal brass $(5.3 \mathrm{~mm})$ nozzleOJB; and then $\mathrm{N}_{2}$-diluted ethylene $(20-80 \%)$ vs air from a "standard" vertical contoured-Pyrex nozzle-OJB $(7.2 \mathrm{~mm})$. The latter system has also been used extensively to characterize the dynamic weakening of the five gaseous $\mathrm{HC}$-air systems [26-29], using steady plus oscillatory velocity inputs at frequencies from 8 to $200 \mathrm{~Hz}$, where virtually all the weakening occurs, and then up to $1600 \mathrm{~Hz}$. Note for all the above $\mathrm{N}_{2}$-diluted $\mathrm{H}_{2}$ and $\mathrm{HC}$ results, extinction limits will show 
asymptotic approaches to nearly constant values as pure fuel is approached. This will indicate extinction limits unaffected by fuel diffusion rates to the airside flames, and hence extinctions limited by chemical kinetic rates. (6) The extinction results for gaseous $\mathrm{HC}$ fuels will be illustrated on a so-called "Idealized Flameholding Scale" consisting of ASRs from nozzle-OJBs plotted versus ASRs from tube-OJBs. This scaling technique will illustrate the relatively large effect of different axial velocity inflow profiles (plug vs parabolic) on ASRs for the various fuels, while maintaining simple proportionality to chemical kinetic reaction rates for the fuels. (7) The FSs of $\mathrm{N}_{2}$-diluted $\mathrm{n}$-heptane and JP-7 mixtures vs air will be shown, and will exhibit the same kinetically limited (asymptotic) behavior as with the gaseous HCs. Also, the $\mathrm{n}$-heptane data will compare favorably with published extinction results (up to a 26 mole \% limit) when the published data, obtained at relatively small gaps, are appropriately corrected, based on Rolon's LDA data. (8) A series of four figures will illustrate the strong effects on FSs of using methane, propane, and ethylene $\mathrm{HCs}$ to dilute $\mathrm{H}_{2}$ (and to "scavenge" $\mathrm{H}$-atoms), compared to the negligible effects of $\mathrm{N}_{2}$ dilution on extinction limits at high $\mathrm{H}_{2}$ concentrations (say, $80 \%-100 \%$ ). The same plots will also show the essentially negligible effects of initial $\mathrm{H}_{2}$ dilution (addition to $\mathrm{HCs}$ ) on FSs at low $\mathrm{H}_{2}$ concentrations (say, $0-20 \%$ ). Finally, (9) a comprehensive "Idealized Flameholding Scale" will be shown that includes all the results discussed above, extends a factor of 50 to pure $\mathrm{H}_{2}$, and includes the effects of $\mathrm{HC}$ reactivity with $\mathrm{H}$-atoms.

\section{Measured and Estimated Strain Rates for Cold Opposed Flows}

Fig. 2 shows a comparison of Rolon's LDA-measured strain rates (SRs) for varying separation of twin $25 \mathrm{~mm}$ diameter contoured nozzles, with fixed flows of air vs air and balanced axial jet momentum flux [33]. Both the measured radial SR, and $-1 / 2$ the measured axial SR, are shown as a function of nozzle separation. In addition, Spalding's suggested approximation [34] for the radial SR, for very large uniform impinging flows, is $U_{\text {air }} / D_{\mathrm{n}}$ (also presently used as ASR for a convergent nozzle); it is only about $15 \%$ low of Rolon's measured values at $H / D \geq 1$. However, the $2 U_{\text {air }} / H$ approximation developed by Williams [35], based on an assumed linear axial velocity gradient and balanced axial momentum fluxes for cold exit flows from large matrix type OJBs (typically $22 \mathrm{~mm}$ diameter), produces a SR that is excessively large under typical operating conditions $(H / D \sim 0.45)$. Thus the reported SRs for the matrix burner are presently reduced by a factor of $\sim 0.42$ to match our short extrapolation of Rolon's measured radial SR ( 45 $1 / \mathrm{s})$. As pointed out by Rolon et. al [33], the $2 U_{\text {air }} / H$ approximation only converges on the measured $-1 / 2$ axial and radial SRs well beyond $H / D>1$, or preferably at $\geq 1.5$. In our subsequent analysis of published $n$-heptane/ $\mathrm{N}_{2}$-air extinction data, derived from a $22 \mathrm{~mm}$ matrix burner [36], we applied the above correction factor of 0.42 to allow a SR data comparison (discussed later).

\section{Nitrogen-diluted Hydrogen-Air Systems}

Fig. 3 shows an early complete set of extinction (Blowoff) and flame restoration (Restore) data for $\mathrm{N}_{2}$-diluted $\mathrm{H}_{2}$ vs air CFDFs using a $2.7 \mathrm{~mm}$ tube-OJB. The physical / chemical effects of $\mathrm{H}_{2}$ dilution by $\mathrm{N}_{2}$ strongly impact both limits. The Blowoff data increase linearly at low $\mathrm{H}_{2}$ concentrations, exhibit progressive non-linearity beyond $50 \% \mathrm{H}_{2}$, and achieve a well-defined horizontal asymptote for 80 to $100 \% \mathrm{H}_{2}$, which establishes a baseline for pure hydrogen (later, it will be shown that the presence of $\mathrm{HCs}$, which typically react with $\mathrm{H}$-atom, completely prevent the attainment of this asymptote). It has been shown earlier $[15,17,9]$ that $U_{\text {air }}$ is an especially relevant measure of CFDF extinction, compared to $U_{\text {fuel }}$, since the asymptotic $U_{\text {air }}$ limit for $\geq 80 \%$ $\mathrm{H}_{2}$ reflects a broad regime of kinetically-limited $\mathrm{H}_{2}$ combustion on the airside, unaffected by diffusion of fuel-jet $\mathrm{N}_{2}$. Coincident with the $U_{\text {air }}$ asymptote, a near doubling of $U_{\text {fuel }}$ reflects the axial-input jet momentum flux balance for centering an ideal OJB flame, i.e., $\rho_{\text {fuel }} U_{\text {fuel }}{ }^{2}=$ $\rho_{\text {air }} U_{\text {air }}{ }^{2}$. This is typically well obeyed by the $2.7 \mathrm{~mm}$ tube-OJB at extinction. The hysteresis between Blowoff and Restore is obviously large, but its magnitude continues to grow proportionally with increased jet size. This is because $U_{\text {air }}$ at Blowoff increases linearly with $D$, 
and $U_{\text {air }}$ at Restore is independent of $D$, for any given $X\left(\mathrm{H}_{2}\right)$ and OJB type, since Restore corresponds to flame propagation just exceeding the outward radial flow of partially premixed fuel and air near the jet edge [9]; see also below.

Fig. 4 shows there is no effect of increasing tube separation ( 5 to 7.5 to $10 \mathrm{~mm}$ ) on extinction and restoration limits of $\mathrm{H}_{2} / \mathrm{N}_{2}$-air CFDFs over a wide range of flowrates $(\sim 5 \mathrm{x})$, using a $5.0 \mathrm{~mm}$ horizontal tube-OJB. The enlarged hysteresis gap between Blowoff and Restore, compared to the $2.7 \mathrm{~mm}$ OJB results, is consistent with extinction $\mathrm{SR}$ being proportional to $U_{\text {air }} / D_{\mathrm{t}}$, as discussed above.

Fig. 5 shows that OJB orientation had no effect on extinction and restoration limits of $\mathrm{H}_{2} / \mathrm{N}_{2}-$ air CFDFs over a substantial range of flowrates, using both vertical and horizontal $7.0 \mathrm{~mm}$ Pyrex tube-OJBs at the "standard" OJB separation of $H / D_{t}=2$. Thus, both Figs. 4 and 5 fully support the subsequent use of horizontal OJBs for $\mathrm{HC}$-air extinction (and restoration) measurements.

Fig. 6 summarizes all the measured ASRs for extinction of $\mathrm{H}_{2} / \mathrm{N}_{2}$-air CFDFs, for a wide range of tube sizes and mostly horizontal orientations. Some upward-deviations of mid-range results from the two smallest OJBs $(1.8$ and $2.7 \mathrm{~mm}$ ) typify the behavior (also seen later for HCs) of flames whose thickness is not small compared to tube diameter, at reduced Reynolds numbers. Note also the extinction-ASRs for tube-OJBs are systematically lower than for convergent nozzleOJBs, due to the large effect of parabolic inflow profiles relative to plug flow profiles [9].

\section{Gaseous Hydrocarbon-Air Systems}

Fig. 7 shows the extinction of $\mathrm{CH}_{4} / \mathrm{N}_{2}$-air CFDFs using a $7.0 \mathrm{~mm}$ vertical-tube-OJB with fuel on top. The data exhibit a mild increase in FS (instead of a nearly flat asymptotic approach) as methane ranges $80 \%$ to $100 \%$. This relatively minor deviation may reflect a tube orientation effect with a relatively weak flame, since data from a horizontal nozzle (shown later) exhibit a nearly flat asymptotic approach.

Fig. 8 shows that tube separation variations from 8 to $22 \mathrm{~mm}\left(1 \leq H / D_{t}>3\right)$ had a negligible effect on FS for pure methane-air CFDFs, using a $7.0 \mathrm{~mm}$ horizontal tube-OJB. In the event that tube separation is reduced somewhat, to accommodate a weak flame that curves slightly upward due to buoyancy, the effect on FS is minimal. The average ASR $(72.31 / \mathrm{s})$ agrees closely with the averaged value for pure methane in Fig. 7 (72.2 1/s).

Fig. 9 summarizes the effect of OJB tube diameter on ASR at extinction for all the gaseous HCs studied thus far; and Fig. 10 shows the same ASR data plotted versus the product, $U_{\text {air, } 300}$ * $D_{\mathrm{t}}$, which effectively simulates the Reynolds number effect for similar gaseous systems. Clearly, the use of excessively small tubes produces ASRs that are artificially high compared to larger tubes, provided that extinction flows remain laminar. Tube diameters of $7 \mathrm{~mm}$ and higher resulted in ASRs that effectively reached horizontal asymptotic extinction limits for the five HCs. Thus the idealized Navier Stokes stream function solution for the 1-D Potential Flow boundary condition appears reasonable for the larger tube sizes and flow rates. Although a minor crossover of the propane-ethane data occurred near $5 \mathrm{~mm}$ diameter in each figure, relative ASRs among the $\mathrm{HC}$-air systems are affected much less by tube diameter than are corresponding absolute values. Notably, the same relative effects have been found for nozzle-OJBs.

Fig. 11 shows respective $\mathrm{FSs}$ for $\mathrm{N}_{2}$-diluted methane-air and propane-air systems derived from an early $5.3 \mathrm{~mm}$ brass horizontal-nozzle OJB. The nearly horizontal asymptotes for 80 to 100 mole \% HC inputs for both fuels indicate (chemical) kinetically limited ASRs that are effectively independent of $\mathrm{HC}$ diffusion rate on the airside, similar to the behavior of $\mathrm{H}_{2}$. Note these extinction ASRs for nozzles with plug inflows are substantially larger than shown earlier (Fig. 7) for tube-OJBs with parabolic inflows (quantified later). 
Finally, Fig. 12 shows FSs for $\mathrm{N}_{2}$-diluted ethylene-air systems, obtained using a "standard" $7.2 \mathrm{~mm}$ vertical Pyrex nozzle-OJB with $14 \mathrm{~mm}$ nozzle spacing. For this system, a horizontal asymptotic FS value for $100 \% \mathrm{C}_{2} \mathrm{H}_{4}$ was estimated. The $\mathrm{FS}$ of ethylene was high enough that the fuel mass flowmeter just exceeded its operational limit. The same OJB system has also been used extensively to characterize dynamic flame weakening caused by sinusoidal velocity inputs of various (driven) amplitudes superimposed on steady inflows, with (mostly) in-phase frequencies ranging from 8 to $1600 \mathrm{~Hz}$ [26-29].

\section{OJB-Extinction "Flameholding Scale" for Gaseous HCs}

Fig. 13 shows the resultant OJB-extinction-limit, linear "Idealized Flameholding Scale" that was obtained for all the present gaseous $\mathrm{HCs}$, using the $7.2 \mathrm{~mm}$ convergent Pyrex nozzle-OJB and the $7.5 \mathrm{~mm}$ straight tube-OJB (except for two sets of methane-air data from a $5.1 \mathrm{~mm}$ Pyrex nozzle and a $5.0 \mathrm{~mm}$ tube). Ethylene exhibits by far the highest Flame Strength (or ASR) of any $\mathrm{HC}$ tested. Note the highly linear relationship, with a slope of 2.51 , represents a best estimate of the effective strain rate ratio for CFDF extinction based on tubes (parabolic inflow), compared with convergent nozzles (plug flow). The same ratio (2.5) also coincides nearly exactly with: (1) the respective axial and radial SR ratios (i.e., parabolic-inflow / plug-inflow) derived for cold flows, using a 2-D numerical simulation [23]; (2) the respective axial $\mathrm{SR}$ ratios derived for $\mathrm{H}_{2}$-air CFDF hot flows, using the same 2-D numerical simulation [23]; and (3) a recently revised analysis [GLP manuscript in preparation] of earlier LDV measurements $[19,9]$ of axial strain rates just upstream of $\mathrm{H}_{2} / \mathrm{N}_{2}$-air CFDFs using the respective $7.5 \mathrm{~mm}$ tubes and $7.2 \mathrm{~mm}$ nozzles.

\section{Extinction of Pure and $\mathrm{N}_{2}$-diluted Vaporized $n$-Heptane, JP-7 and JP-10 Fuels}

Fig. 14 shows the results obtained for vaporized, and also nitrogen-diluted, n-heptane and JP-7 fuels $[24,25]$. The apparatus and general procedures used are shown and described in Fig. 1c. The respective ASRs increase substantially with increasing $\mathrm{HC}$ mole fraction up to about 75 mole \%; thereafter, the ASRs attain respective horizontal asymptotic values, just as the gaseous $\mathrm{HCs}$ and hydrogen did. The asymptotes suggest, as before, chemical kinetic-limited ASRs, because each are unaffected by significant changes in nitrogen dilution. Although these neat fuels are of higher molecular weight and lower diffusivity than the gaseous $\mathrm{HCs}$ and $\mathrm{H}_{2}$, and the axial-momentum-balanced flames (w/inputs of $\rho_{\text {air }}{ }^{*} U_{\text {air }}{ }^{2}=\rho_{\text {fuel }}{ }^{*} U_{\text {fuel }}{ }^{2}$ ) should lie closer to the stagnation point, it still seems likely that pyrolysis and combustion-with-diffusion of lower molecular weight fuel species in the airside flame should continue being affected by nitrogen diffusion from the fuel side.

The solid points in Fig. 14, which agree quite closely with the present n-heptane data, represent substantially corrected experimental results originally published by Seiser et. al [36], who used a $22 \mathrm{~mm}$ diameter matrix-OJB with a gap of $H=10 \mathrm{~mm}$. Thus the original (plotted) results were corrected to be comparable with the present ASR scale for a $7.5 \mathrm{~mm}$ tube-OJB. This correction has two parts. First, based on Rolon's measurements of axial and radial SRs as a function of nozzle separation distance [33], discussed earlier with Fig. 2, a correction factor of 0.42 was applied to the Ref. [36] matrix-OJB SR results of $5001 / \mathrm{s}$ for $25 \mathrm{~mole} \% n$-heptane $/ \mathrm{N}_{2}-$ air, and $4001 / \mathrm{s}$ for 18 mole $\% n$-heptane/ $\mathrm{N}_{2}$-air. The 0.42 factor estimates the actual radial (and $-1 / 2$ axial) SRs that existed at $H / D_{\text {burner }}=0.45$, as a correction of the "standard" SR expression for a matrix-type burner, $2 U_{\text {air }} / H$, that assumes a linear SR profile and an axial momentum balance for cold inflows. Next, SRs from the first stage of correction, which allow comparison with uniform-velocity (plug flow) ASRs from a convergent nozzle, were divided by a factor of 2.5. This equals both the experimentally- and numerically-derived factor (discussed above) that converts plug inflow ASRs for hydrocarbon-air systems to equivalent parabolic-inflow ASRs with the same radial strain rate in the flame core [23, and GLP et. al unpublished manuscript]. Note, because the equivalent $H / D_{\text {burner }}=0.45$ separation of $11.25 \mathrm{~mm}$ in Fig. 2 is smaller than Rolon's smallest separation $(15 \mathrm{~mm})$, and Rolon's flows were cold, the first part of the correction is slightly uncertain. 
Figs. 15 and 16 show some of the original batch-process liquid-vaporization data used to produce $n$-heptane $/ \mathrm{N}_{2}$ mixtures at elevated temperature and pressure, in preparation for subsequent multiple determinations (typically 8 to 10 acceptable measurements) after heat-up and stabilization of the nitrogen-purged combustion chamber $[24,25]$.

\section{Reactivity of Hydrogen plus HC mixtures}

Figs. 17-19 show extinction data for $\mathrm{HC}$-diluted $\mathrm{H}_{2}$ vs air, where methane, propane, and ethylene are used, respectively, to dilute pure hydrogen. All three sets of results show a dramatic decrease in FS as $\mathrm{HC}$ is added initially; and this also leads to a rapid convergence of Blowoff and Restore limits [16]. These initial decreases can be compared directly with the Fig. 3 results for $\mathrm{N}_{2}$ dilution, which exhibit an unchanging asymptotic $\mathrm{FS}$ from $80-100$ mole $\% \mathrm{H}_{2}$. The physical explanation for these dramatic decreases in FS is these simple $\mathrm{HCs}$ are very effective in scavenging $\mathrm{H}$-atoms that normally form, diffuse rapidly on the airside, and dominate flame reactivity. Thus the reduction in $\mathrm{H}$-atom (and $\mathrm{OH}$ ) greatly reduces $\mathrm{FS}[16,9]$. Also, at the $\mathrm{HC}$-rich (left) end, as $\mathrm{H}_{2}$ is initially added to each $\mathrm{HC}$, the data show very little increase in $\mathrm{FS}$ as $\mathrm{H}_{2}$ increases 0 to $20 \%$. In a similar vein, $\mathrm{H}$-atoms resulting from incremental $\mathrm{H}_{2}$ addition are so effectively scavenged by $\mathrm{HCs}$ that $\mathrm{FS}$ is totally dominated by the $\mathrm{HC}$. Both of these results have significant implications with respect to any contemplated use of $\mathrm{HC}$ plus $\mathrm{H}_{2}$ mixed fuels, whether at the $\mathrm{H}_{2}$-rich end (used to retard combustion), or at the $\mathrm{HC}$-rich end (e.g. barbatage). And finally, ignition of mixed $\mathrm{HC}$ plus $10 \% \mathrm{H}_{2}$ fuels has been found to exhibit similar behavior [3].

\section{Comprehensive "Idealized Flameholding Scale" for $\mathrm{HCs}, \mathrm{H}_{2}$ and Mixtures}

Fig. 20 shows a major extension of the Fig. 13 linear "Idealized Flameholding Scale" obtained for simple gaseous HCs. As before, the $7.2 \mathrm{~mm}$ Pyrex nozzle- and the $7.5 \mathrm{~mm}$ straight tubeOJBs characterize each of the simple HCs. However, the plot also contains additional $100 \% \mathrm{H}_{2}$ data, $\mathrm{HC}$-plus- $\mathrm{H}_{2}$ data extracted from the high-FS regions of Figs. 17 and 19, and also three sets of recent pure- and nitrogen-diluted vaporized-liquid FS data. The latter data for 100\% JP-10-air, and both pure and nitrogen-diluted JP-7 and $n$-heptane vs air, were obtained as part of a recent MS thesis by JLC [25], and this followed a paper presented near the mid-point of the study [24].

In Fig. 20, $100 \% \mathrm{H}_{2}$, which produces a unique and exceptionally strong flame, bounds the upper end of the flameholding scale. Both data points (averaged from previous $2.7 \mathrm{~mm}$ Pyrex nozzle- and $2.7 \mathrm{~mm}$ tube-OJB data; and obtained from a recent $2.91 \mathrm{~mm}$ tube-OJB) agree within about $1 \%$ of Hwang's recent 2-D numerically simulated FSs for hydrogen-air extinction, for a 3 $\mathrm{mm}$ tube-OJB configuration with appropriate guard flows and disk-shaped boundary conditions [23]. For all the data points marked with a pound sign (\#), measurements made with respective $7.5 \mathrm{~mm}$ and $2.7 \mathrm{~mm}$ tube-OJBs were plotted on a least-squares fit of all the gaseous HC data, plus the early data for pure $\mathrm{H}_{2}$ from $2.7 \mathrm{~mm}$ nozzle- and $2.7 \mathrm{~mm}$ tube-OJBs. Although the linear slope increased from 2.51 to 2.73 due to addition of the pure $\mathrm{H}_{2}$ data, the former slope (2.51) is now considered most appropriate for HC CFDFs. This is largely due to a now recognized downstream shift in the average $\mathrm{HC}$ flame location, on the airside, relative to that for hydrogen [GLP manuscript in preparation].

Based on the above FS characterizations, and the very wide range of reactivity exhibited on the Idealized Flameholding Scale of Fig. 20, we conclude that the experimental ASR's, and/or ratios of ASR's for various neat and blended hydrocarbons with and without additives, represent relative global chemical kinetic limits. As such, the ASRs can provide absolute and relative tests of the validity of reduced chemical kinetic models, when applied at the appropriate pressures and peak temperatures of extinction.

\section{Comparison of Flame Strengths with Laminar Burning Velocities}

Fig. 21 compares ASRs for all the gaseous-HC extinction limits, from the $7.5 \mathrm{~mm}$ tube-OJB, with recently surveyed / published unstrained laminar burning velocity, $S_{L, 0}$, measurements 
$[37,38]$ at an equivalence ratio of unity $(\mathrm{phi}=1)$. And, Fig. 22 extends the ASR results of Fig. 21 all the way to $100 \% \mathrm{H}_{2}$. Clearly, the ASRs reflect considerably more sensitivity to changes in fuel molecular size and reactivity than $S_{\mathrm{L}, 0}$ does. In Fig. 21, a linear fit of the ASR vs $S_{\mathrm{L}, 0}$ data leads to a slope of 3.64, which seems inappropriately small for the (four lowest) saturated HCs. And in Fig. 22, a power-law fit of the gaseous- $\mathrm{HC}+\mathrm{H}_{2}$ data seemed to represent the only reasonable fit of the data. In this case a power law exponent of 1.87 fit the overall data quite well. This further demonstrates a strong apparent "dependence" of ASR on $S_{\mathrm{L}, 0}$. Thus, in conclusion, we find that burning velocity changes only weakly against strain-sensitive $F S$ variations, and this leads us to recommend that laminar burning velocity is a relatively insensitive and unsatisfactory measure of fuel reactivity changes, for use in assessing "idealized" flameholding at atmospheric pressure.

\section{Summary and Conclusions}

This paper details the normalization of $\mathrm{FSs}$ of $\mathrm{N}_{2}$-diluted $\mathrm{H}_{2}$ and $\mathrm{HC}$ systems to account for effects of fuel composition, temperature, pressure, jet diameter, inflow Reynolds number, and inflow velocity profile (plug, contoured nozzle; parabolic, straight tube). Normalized results exemplify a sensitive accurate means of validating, globally, reduced chemical kinetic models at $1 \mathrm{~atm}$ and temperatures approximating the loss of non-premixed "idealized" flameholding, e.g., in scramjet combustors.

Laminar FS is defined locally as maximum air input velocity, $U_{\text {air }}$, that sustains combustion of a counter-jet of g-fuel at extinction. It uniquely characterizes a fuel. And global axial strain rate at extinction $\left(U_{\text {air }}\right.$ normalized by nozzle or tube diameter, $D_{n}$ ort $)$ can be compared directly with computed extinction limits, determined using either a 1-D Navier Stokes stream-function solution, using detailed transport and finite rate chemistry, or a detailed 2-D Navier Stokes numerical simulation. The experimental results define an "idealized flameholding reactivity scale" that shows wide ranging $(50 \mathrm{x})$ normalized FS's for various vaporized-liquid and gaseous HCs, including, in ascending order: JP-10, methane, JP-7, $n$-heptane, $n$-butane, propane, ethane, and ethylene. Results from $\mathrm{H}_{2}$-air produce a unique and exceptionally strong flame that now agree within about $1 \%$ of a recent 2-D numerically simulated $\mathrm{FS}$ for a $3 \mathrm{~mm}$ tube-OJB. Thus we suggest that experimental FS's and/or FS ratios, for various neat and blended $\mathrm{HCs} \mathrm{w} /$ and w/o additives, offer accurate global tests of chemical kinetic models at the temperatures and pressures of extinction.

We conclude the FS approach is more direct and fundamental, for assessing, e.g., idealized scramjet flameholding potentials, than measurements of laminar burning velocity or blowout in a Perfectly Stirred Reactor, because they characterize premixed combustion in the absence of aerodynamic strain. And FS directly measures a chemical kinetic characteristic of non-premixed combustion at typical flameholding temperatures. It mimics conditions where gaseous fuels are typically injected into a subsonic flameholding recirculation zone that captures air, where the effects of aerodynamic strain and associated multi-component diffusion are important.

Based on the above results, we advocate that a remotely operated OJB system be developed to achieve real-time (e.g., 1 minute) characterizations of the idealized flameholding potential (FS) of high-T, high-pressure, multi-component, vaporized-hydrocarbon fuels being used for scramjet testing. Results should also be compared with other relevant sources of vaporized HCs, e.g., fuels processed by simple bench top vaporizer / catalytic cracking systems, or fuels captured by "freezing" the composition of a cracked vaporized (superfluid) HC from a heater / vaporizer / catalytic-cracking system. Thus we propose that measurements of FS could be, and should be, a key routine $\mathrm{HC}$ fuel characterization parameter for any scramjet combustor test. Similar logic may be applied to the development of any surrogate $\mathrm{HC}$ fuel mixture, such that its measured $\mathrm{FS}$ mimics that of a typical uncracked- and also cracked fuel, and its FS can be numerically simulated for a known composition, using available chemical kinetics and a detailed OJB code. 


\section{References}

1. Maurice, L.Q., Corporan, E., Minus, D., Mantz, R., Edwards, T., Wohlwend, K. Harrison, W.E., Striebich, R.C., Sidhu, S. Graham, J., Hitch, B., Wickham, D, and Karpuk, M., "Smart Fuels: "Controlled Chemically Reacting Fuels," AIAA Paper AIAA 99-4916, July, 1999, 11 pp.

2. Wickham, D.T., Alptekin, G.O., Engel, J.R., and Karpuk, M.E., "Additives to Reduce Coking in Endothermic Heat Exchangers," AIAA Paper AIAA 99-2215, July, 1999, 9 pp.

3. Colket, M.B., III, and Spadaccini, L.J., "Scramjet Fuels Autoignition Study," J.

Propulsion and Power, 17, No. 2, 2001, Mar.-Apr. 2001pp. 315-323.

4. Gruber, M. Dunbar, J., and Jackson, K., "Newly Developed Direct-Connect HighEnthalpy Supersonic Combustion Research Facility," J. Propulsion and Power, 17, No. 6, Nov.-Dec. 2001, pp. 1296-1304.

5. Mathur, T., Gruber, M., Jackson, K., Donbar, J., Donaldson, W., Jackson, T., and Billig. F., "Supersonic Combustion Experiments with a Cavity-Based Fuel Injector," J. Propulsion and Power, 17, No. 6, Nov.-Dec. 2001, pp. 1305-1312.

6. Rasmussen, C.C., Driscoll, J.F., Hsu, Kuang-Yu, Donbar, J.M., Gruber, M.R., and Carer, C.D., "Stability Limits of Cavity-Stabilized flames in Supersonic Flow," Proceedings of the Combustion Institute 30 (2005), 2825-2833.

7. Cooke, J.A., Bellucci, M., Smooke, M.d., Gomez, A., Violi, A., Faravelli, T. and Ranzi, E., "Computational and Experimental Study of JP-8, a Surrogate, and its Components in Counterflow Diffusion Flames," Proceedings of the Combustion Institute 30 (2005), 439446.

8. Maurice, L.Q, Edwards, T., Cuoco, F. Bruno, C, and Hendrick, P., CHAPTER 2: Fuels, in Technologies for Propelled Hypersonic Flight, RTO-TR-AVT-007, Volume 2 Subgroup 2: Scram Propulsion, ISBNs 978-92-837-0041-4 / 978-92-837-0041-8, Jan. 2006, pp. 2-1 through 2-35.

9. Pellett, G.L., Isaac, K.M., Humphreys, W.M., Jr., Gartrell, L.R., Roberts, W.L., Dancey, C.L., and Northam, G.B., "Velocity and Thermal Structure, and Strain-Induced Extinction of 14 to $100 \%$ Hydrogen-Air Counterflow Diffusion Flames," Combust. Flame 112, No. 4, 1998, pp. 575-592.

10. Pellett, G.L., Northam, G.B., Guerra, R., and Wilson, L.G., "Opposed Jet Burner Studies of Silane-Methane, Silane-Hydrogen, and Hydrogen Diffusion Flames with Air," CPIA Publication 457, Vol. 1, Oct. 1986, pp. 391-404.

11. Pellett, G.L., Northam, G.B., Wilson, L.G., "Counterflow Diffusion Flames of Hydrogen, and Hydrogen Plus Methane, Ethylene, Propane, and Silane, vs. Air: Strain Rates at Extinction," AIAA Paper 91-0370, Jan. 1991, 17 pp.

12. Guerra, Rosemary, Pellett, G.L., Wilson, L.G., Northam, G.B., "Opposed Jet Burner Studies of Hydrogen Combustion with Pure and $\mathrm{N}_{2}$, NO Contaminated Air," AIAA Paper 87-0090, Jan. 1987, 11 pp. 
13. Guerra, Rosemary, Pellett, G.L., Wilson, L.G., Northam, G.B., "Opposed Jet Burner Studies of Effects of $\mathrm{CO}, \mathrm{CO}_{2}$ and $\mathrm{N}_{2}$ Air Contaminants on Hydrogen-Air Diffusion Flames," AIAA Paper 87-1960, July 1987, 14 pp.

14. Pellett, G.L., Jentzen, M.E., Wilson, L.G., and Northam, G.B., "Effects of WaterContaminated Air on Blowoff Limits of Opposed Jet Hydrogen-Air Diffusion Flames," AIAA Paper 88-3295, July 1988, 10 pp.

15. Pellett, G.L., Wilson, L.G., Northam, G.B., Guerra, Rosemary, "Effects of $\mathrm{H}_{2} \mathrm{O}, \mathrm{CO}_{2}$, and $\mathrm{N}_{2}$ Air Contaminants on Critical Airside Strain Rates for Extinction of Hydrogen-Air Counterflow Diffusion Flames," CPIA Publication 529, Vol. II, (Oct., 1989), pp. 23-42.

Pasadena, CA, Oct., 1989.

16. Pellett, G.L., Northam, G.B., Wilson, L.G., "Counterflow Diffusion Flames of Hydrogen, and Hydrogen Plus Methane, Ethylene, Propane, and Silane, vs. Air: Strain Rates at Extinction," AIAA Paper 91-0370, Jan., 1991, 17 pp.

17. Pellett, G.L., Northam, G.B., Wilson, L.G., "Strain-Induced Extinction of HydrogenAir Counterflow Diffusion Flames: Effects of Steam, $\mathrm{CO}_{2}, \mathrm{~N}_{2}$, and $\mathrm{O}_{2}$ Additives to Air," AIAA Paper 92-0877, Jan., 1992, 15 pp. (Also a manuscript in preparation on these and recent 2-D numerical results.)

18. Pellett, G. L., Roberts, W. L., Wilson, L. G., Humphreys, W. M., Jr., Bartram, S. M., Weinstein, L. M., and Isaac, K. M., "Structure of Hydrogen-Air Counterflow Diffusion Flames Obtained by Focusing Schlieren, Shadowgraph, PIV, Thermometry, and Computation," AIAA Paper 94-2300, June 1994, 23 pp.

19. Pellett, G. L., Wilson, L. G., Humphreys, W. M.,Jr., Bartram, S. M., Gartrell, L. R., and Isaac, K. M., Roberts, W. L., IV, and Northam, G. B., "Velocity Fields of Axisymmetric Hydrogen-Air Counterflow Diffusion Flames from LDV, PIV, and Numerical Computation," AIAA paper 95-3112, July 1995, 23 pp.

20. Isaac, K. M., Ho, Y. H., Zhao, J., Pellett, G. L., and Northam, G. B., "Global Characteristics and Structure of Hydrogen-Air Counterflow Diffusion Flames: A One-Dimensional Model," AIAA Paper 94-0680, Jan.,1994. Also, Zhao, J., Isaac, K. M., and Pellett, G. L., J. Propul. Power 12, No. 3: 534-542 (1996).

21. Pellett, G.L., Bruno, C., and Chinitz, W., "Review of Air Vitiation Effects on Scramjet Ignition and Flameholding Combustion Processes," AIAA Paper 2002-3880, July 2002, 37 pp.

22. Pellett, G.L., Bruno, C, and Chinitz, W., CHAPTER 4: Air Vitiation Effects on Scramjet Combustion Tests, in Technologies for Propelled Hypersonic Flight, RTO-TRAVT-007, Volume 2 - Subgroup 4: Scram Propulsion, ISBNs 978-92-837-0041-4 / 97892-837-0041-8, Jan. 2006, pp 4-1 through 4-21.

23. Hwang, Kyu C., "Two Dimensional Numerical Simulation of Highly-Srained Hydrogen-Air Opposed Jet Laminar Diffusion Flames," Ph. D. Dissertation, Old Dominion University, Norfolk, VA, May 2003.

24. Convery, J.L., Pellett, G.L., O' Brien, W.F., and Wilson, L.G., "An Experimental Study of $n$ Heptane and JP-7 Extinction Limits in an Opposed Jet Burner," AIAA Paper 2005-3766, July 2005, 8 pp.

25. Convery, J.L., "An Experimental Investigation of JP-7 and $n$-Heptane Extinction Limits in an Opposed Jet Burner," MS Thesis in Mechanical Engineering, Virginia Polytechnic Institute and State University, Blacksburg, VA, October 27, 2005, 52 pp. 
26. Pellett, G.L., Reid, Beth, McNamara, Clare, Johnson, Rachel, Kabaria, Amy, Panigrahi, Babita, and Wilson, L.G., "Acoustic Weakening of Methane-, Ethylene-, and Hydrogen-Air Counterflow Diffusion Flames, and Implications for Scramjet Flameholding." AIAA Paper 20034634, July 2003, 21 pp.

27. Pellett, G., Reid, B., McNamara, C., Johnson, R., Kabaria, A., Panigrahi, B., Sammons, K., and Wilson, L., "Dynamic Weakening of $\mathrm{CH}_{4}-, \mathrm{C}_{2} \mathrm{H}_{6}-$, and $\mathrm{C}_{2} \mathrm{H}_{4} / \mathrm{N}_{2}-$ Air Counterflow Diffusion Flames using Acoustically Perturbed Inflows." Work-in-Progress Poster Paper 4F504, Presented at $30^{\text {th }}$ International Symposium on Combustion, Abstracts of Work-In-Progress Posters, The Combustion Institute, Pittsburgh, PA, July 25-30, 2004.

28. Pellett, G.L., Kabaria, A., Panigrahi, B., Sammons, K., Convery, J., and Wilson, L.G., "Dynamic Weakening (Extinction) of Simple Hydrocarbon-Air Counterflow Diffusion Flames by Oscillatory Inflows." AIAA Paper 2005-4332, July 2005, 22pp.

29. Pellett, G.L, McNamara, C., Johnson, R., Kabaria, A., Panigrahi, B., Sammons, K., Galgano, J., and Wilson, L.G., "Dynamic Weakening of Gaseous Hydrocarbon (C1-C4)-Air Counterflow Diffusion Flames by Oscillatory Inflows," to be presented at $31^{\text {st }}$ International Symposium on Combustion, Abstracts of Work-In-Progress Poster Presentations, Poster 4B01, The Combustion Institute, Pittsburgh, PA, Aug. 6-11, 2006.

30. Guthhel, E., and Williams, F., $23^{\text {rd }}$ Symposium (International) on Combustion, The Combustion Institute, Pittsburgh, 1990, p. 513.

31. Guthhel, E., Balakrishnan, G., and Williams, F., in Reduced Kinetic Mechanisms for Application in Combustion Systems, Lecture Notes in Physics (N. Peters and B. Rogg, eds.) Springer-Verlag, New York, 1992, p. 177.

32. Pellett, G.L., Isaac, K.M., and Nguyen, G., "Effect of Input Temperature on Strain-Induced Extinction of 50 to $100 \%$ Hydrogen-Air Counterflow Diffusion Flames," Presented at $27^{\text {th }}$ Symposium (International) on Combustion, Abstracts of Work-In-Progress Poster Presentations, The Combustion Institute, Pittsburgh, PA, Poster W2D01, Aug., 1998, p. 192.

33. Rolon, J.C., Veynante, D., Martin, J.P., and Durst, E., "Counter Jet Stagnation Flows," Experiments in Fluids, 11, (1991), pp. 313-324.

34. Spalding, D.B., "Theory of Mixing and Chemical Reaction in the Opposed-Jet Diffusion Flame," J. Amer. Rocket Soc., 3 (1961), pp. 763-771.

35. Williams, F.A., "A Review of Flame Extinction," Fire Safety J., 3 (1981), pp. 163-175.

36. Seiser, R., Truett, L., Trees, D., and Seshadri, K., "Structure and Extinction of Non-premixed $n$-Heptane Flames," $27^{\text {th }}$ Symposium (International) on Combustion, The Combustion Institute (1998), pp. 649-657.

37. Bosschaart, K.J., and de Goey, L.P.H., "The Laminar Burning Velocity of Flames Propagating in Mixtures of Hydrocarbons and Air Measured with the Heat Flux Method," Combustion and Flame, 136 (2004) pp. 261-269.

38. Hassan, M.I., Aung, K.T., Kwon, O.C., and Faeth, G.M., "Properties of Laminar Premixed Hydrocarbon / Air Flames at Various Pressures," J. Propulsion and Power, 14, No. 4 (1998), pp. 479-488. 


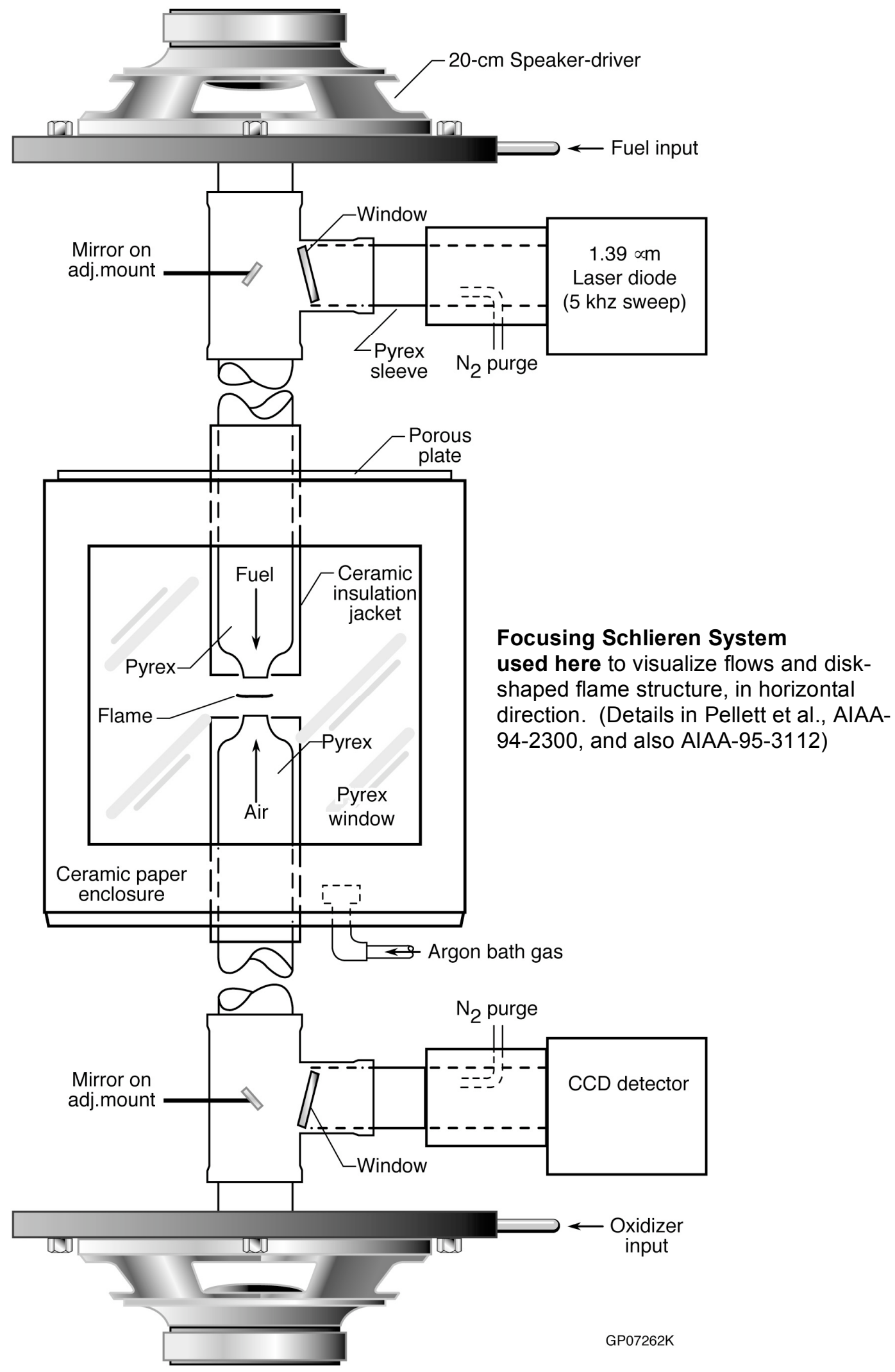

Fig. 1a. Schematic of Oscillatory Opposed Jet Burner (OOJB) system with twin $20-\mathrm{cm}$ speaker-drivers. Diode laser system is passive in this study. 


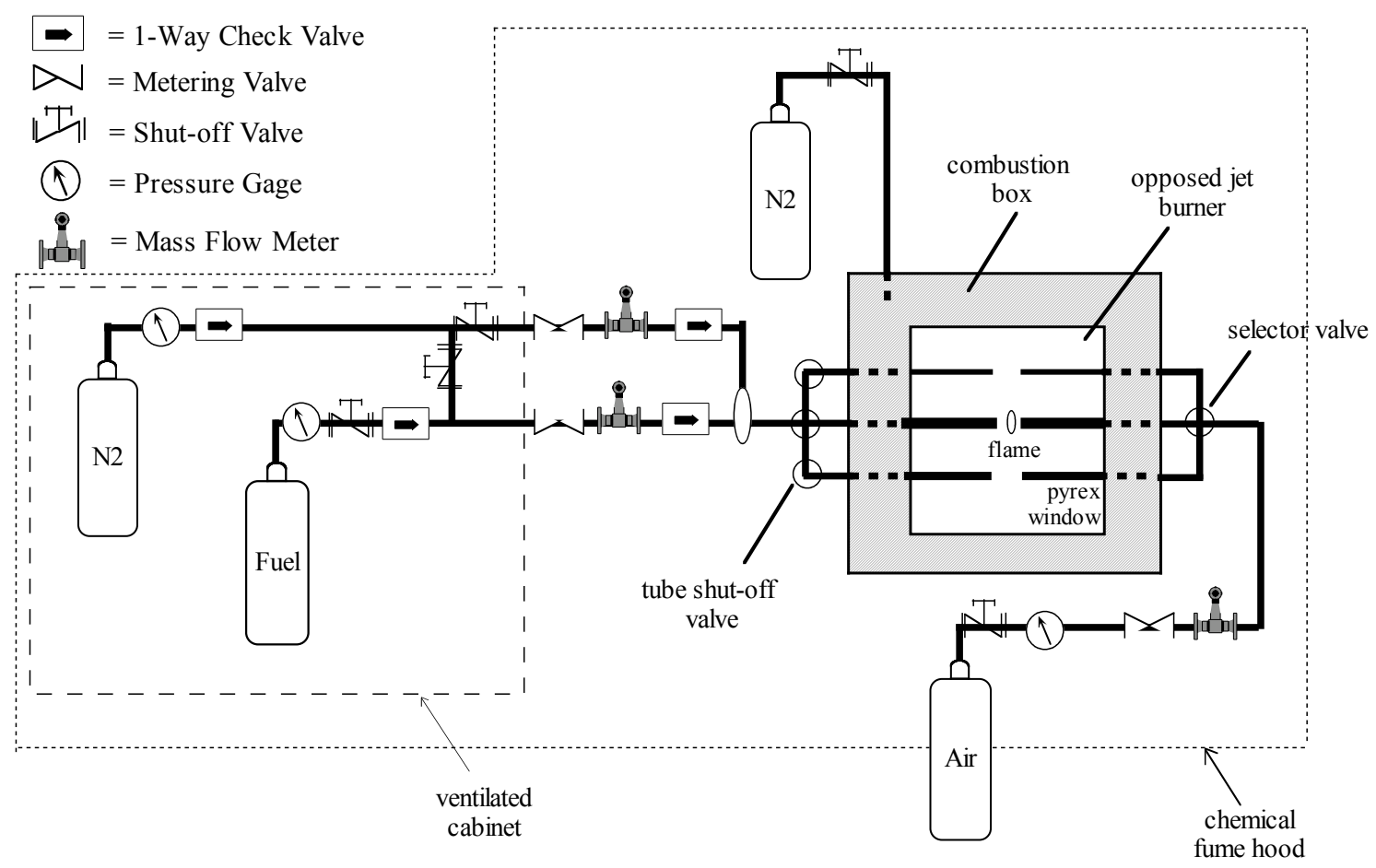

Fig. 1b. Gaseous-Fuel Horizontal-Tube Opposed Jet Burner (OJB) test schematic (not to scale). Combustion box, constructed of 0.5 in thick compacted silica fiber-board panels, has a porous metal plate on top -- typically $4 \times 6$ in is exposed and "active". Thus combustion products are actively purged by controlled nitrogen flows from two porous plug outlets at opposite corners of the box floor. The three matching sets of tube-OJBs are actually arrayed in a horizontal plane, not vertically as shown. Mass flows of fuel, fuel-diluent, and air are monitored more or less continuously as flame extinction and restoration limits are approached and achieved.

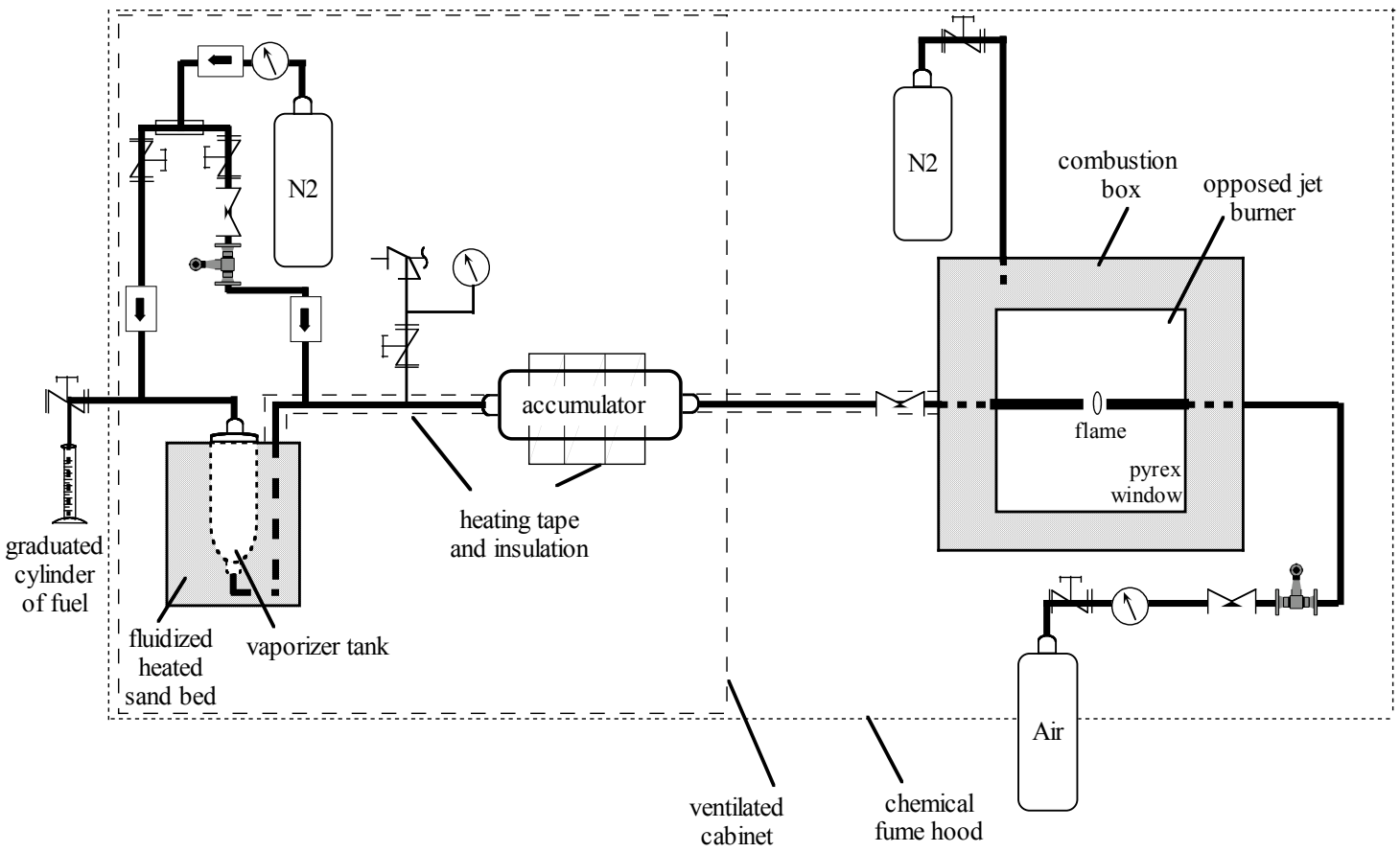

Fig. 1c. Liquid Fuel Opposed Jet Burner test schematic (not to scale). Silica fiber combustion box, with porous plate on top, is identical to that in Fig. $1 \mathrm{~b}$. Vaporizer tank is $0.5 \mathrm{~L}$ and accumulator tank is $9.5 \mathrm{~L}$. For each batch test (set), a known volume of liquid $\mathrm{HC}$ is injected into the cold, evacuated system. Then mass-flow-metered fuel diluent (either $\mathrm{N}_{2}$ or gaseous $\mathrm{HC}$ ) is admitted, up to a specific pressure. Finally, the system is sealed and heated to a measured (multipoint averaged) temperature and pressure, and held there to assure mixing, before it is operated in a "blow down mode" to supply the $7.5 \mathrm{~mm}$ tube-OJB system. For the vaporized liquid $\mathrm{HC}$ experiments, air mass flows are monitored, but the mass flows of fuel mixture are generally not monitored due to temperature limitations. 


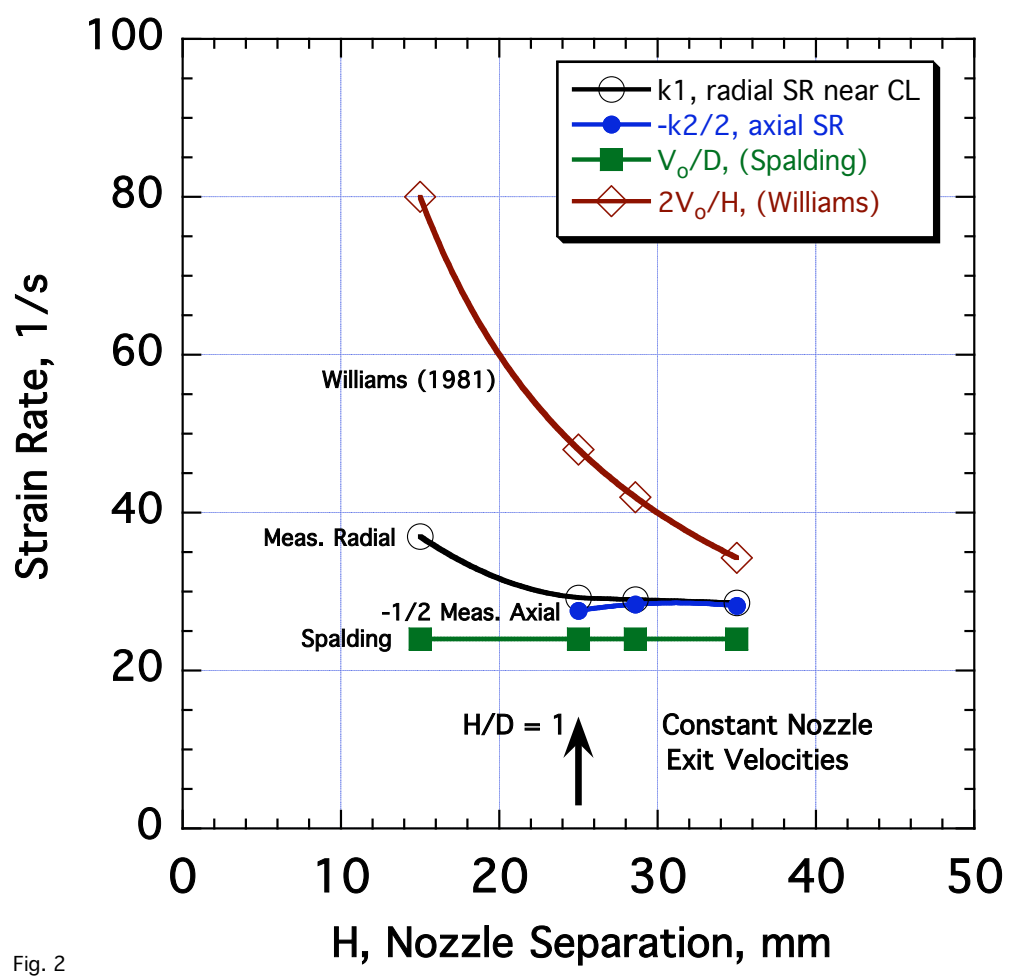

Fig. 2. Comparison of Rolon's LDA-Measured Strain Rates for Variable Separation of $25 \mathrm{~mm}$ Contoured Nozzles, Air vs Air. Rolon et. al, Exp. in Fluids, 11 (1991) pp. 313-324.

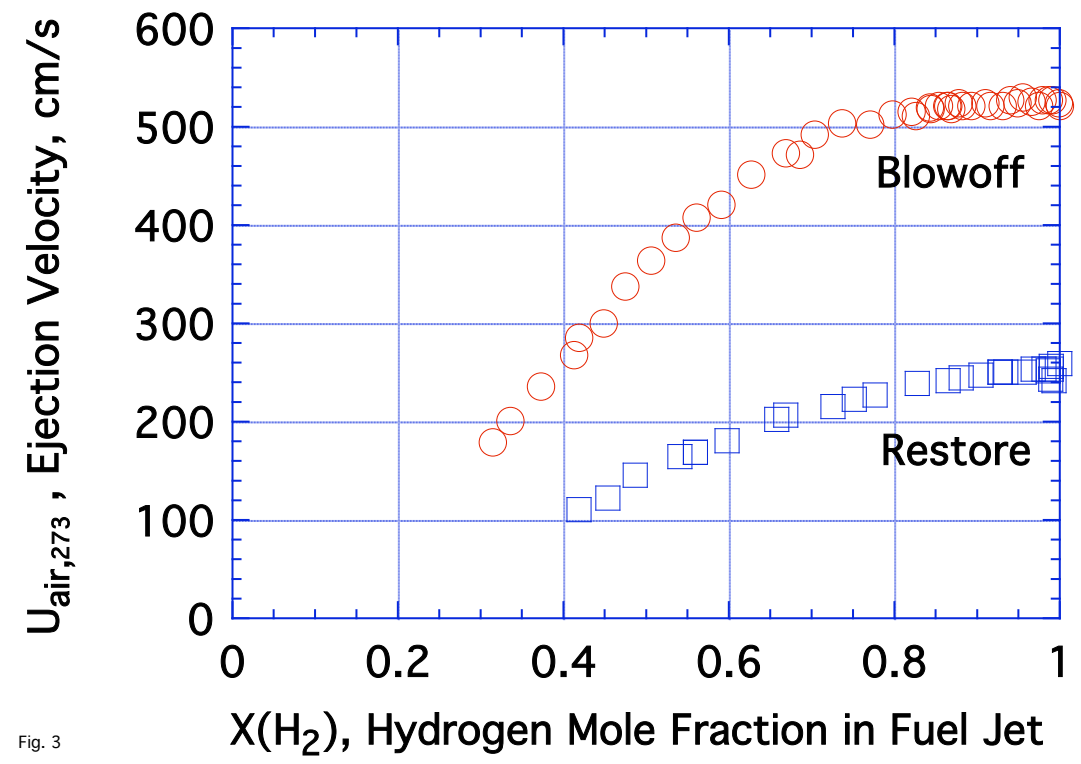

Fig. 3. Air Flows, Extinction and Restoration of $\mathrm{N}_{2}$-diluted $\mathrm{H}_{2}$ vs Air CFDFs, using $2.7 \mathrm{~mm}$ Horizontal-Tube-Opposed Jet Burner. 


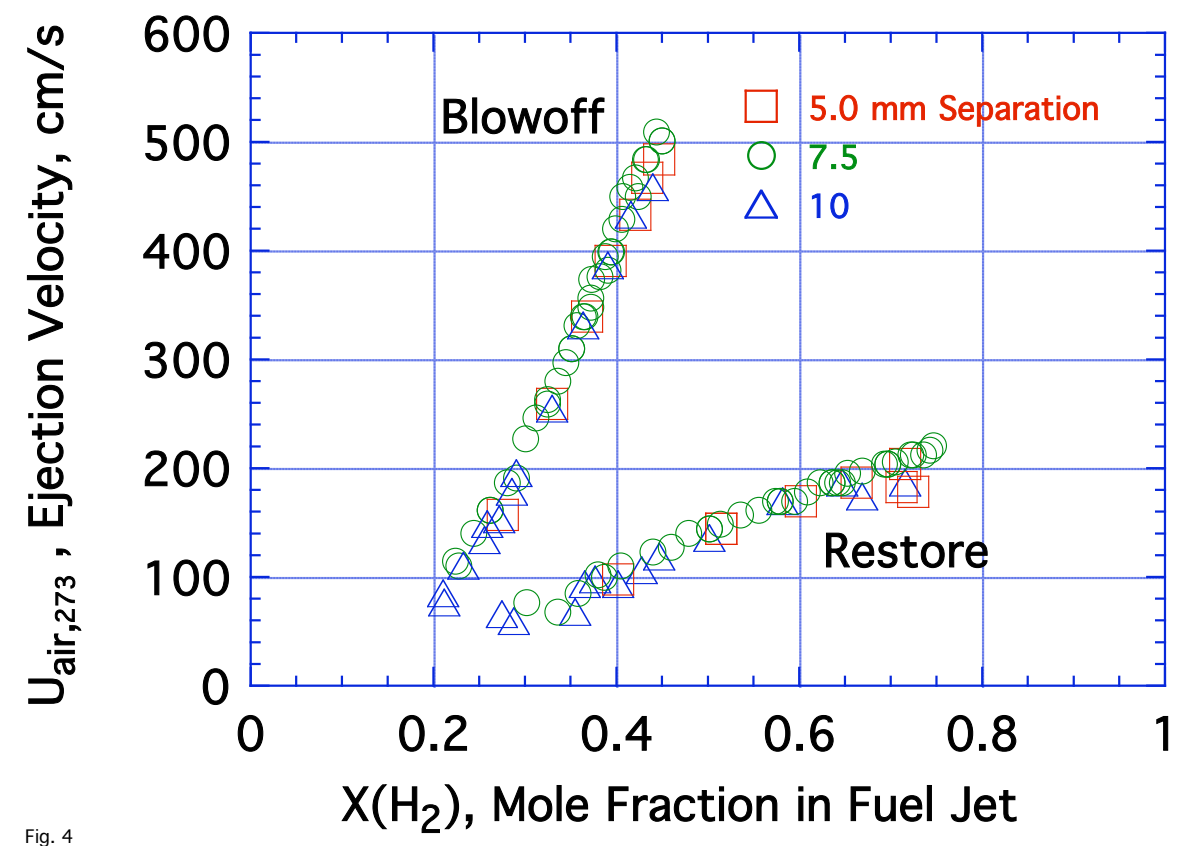

Fig. 4. Effect of Tube Separation on Extinction and Restoration of $\mathrm{H}_{2} / \mathrm{N}_{2}$-Air CFDFs, using $5.0 \mathrm{~mm}$ Horizontal-Tube-OJB.

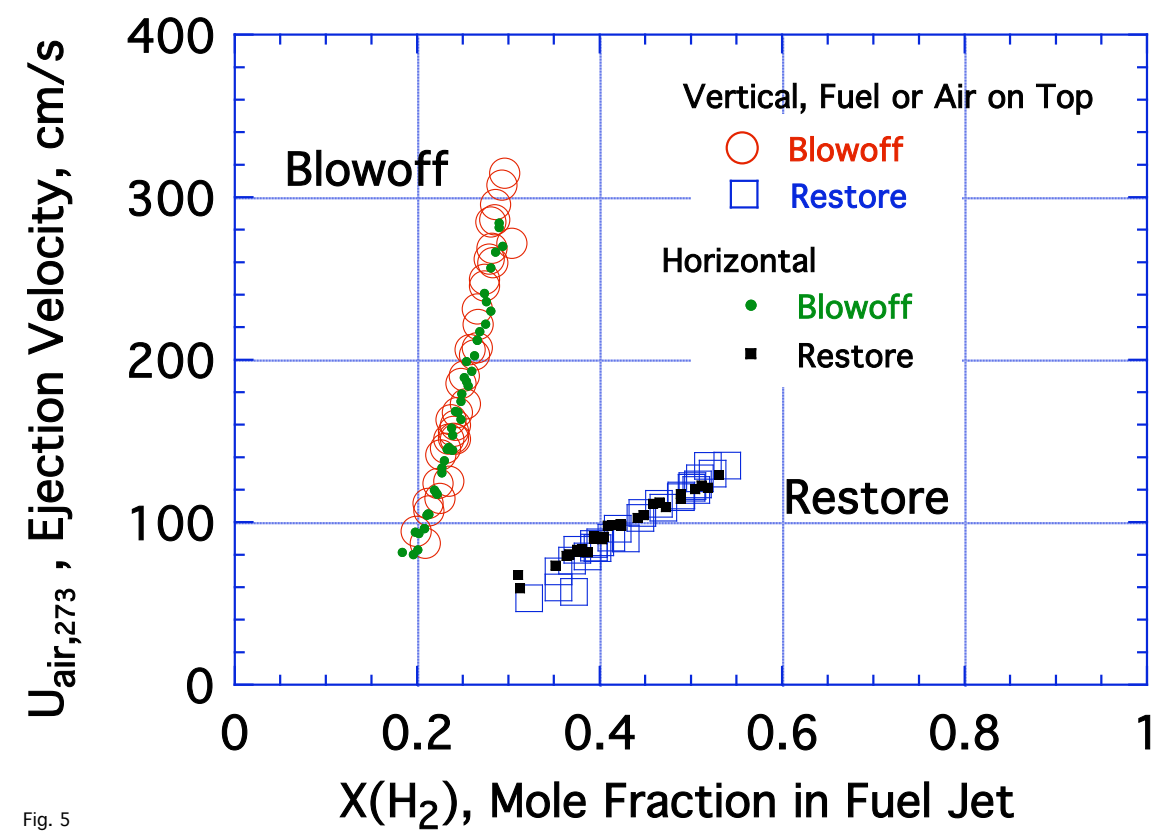

Fig. 5. Effect of Orientation on Extinction \& Restoration of $\mathrm{H}_{2} / \mathrm{N}_{2}$-Air CFDFs, using Vertical \& Horizontal $7.0 \mathrm{~mm}$ Pyrex Tube-OJBs. 


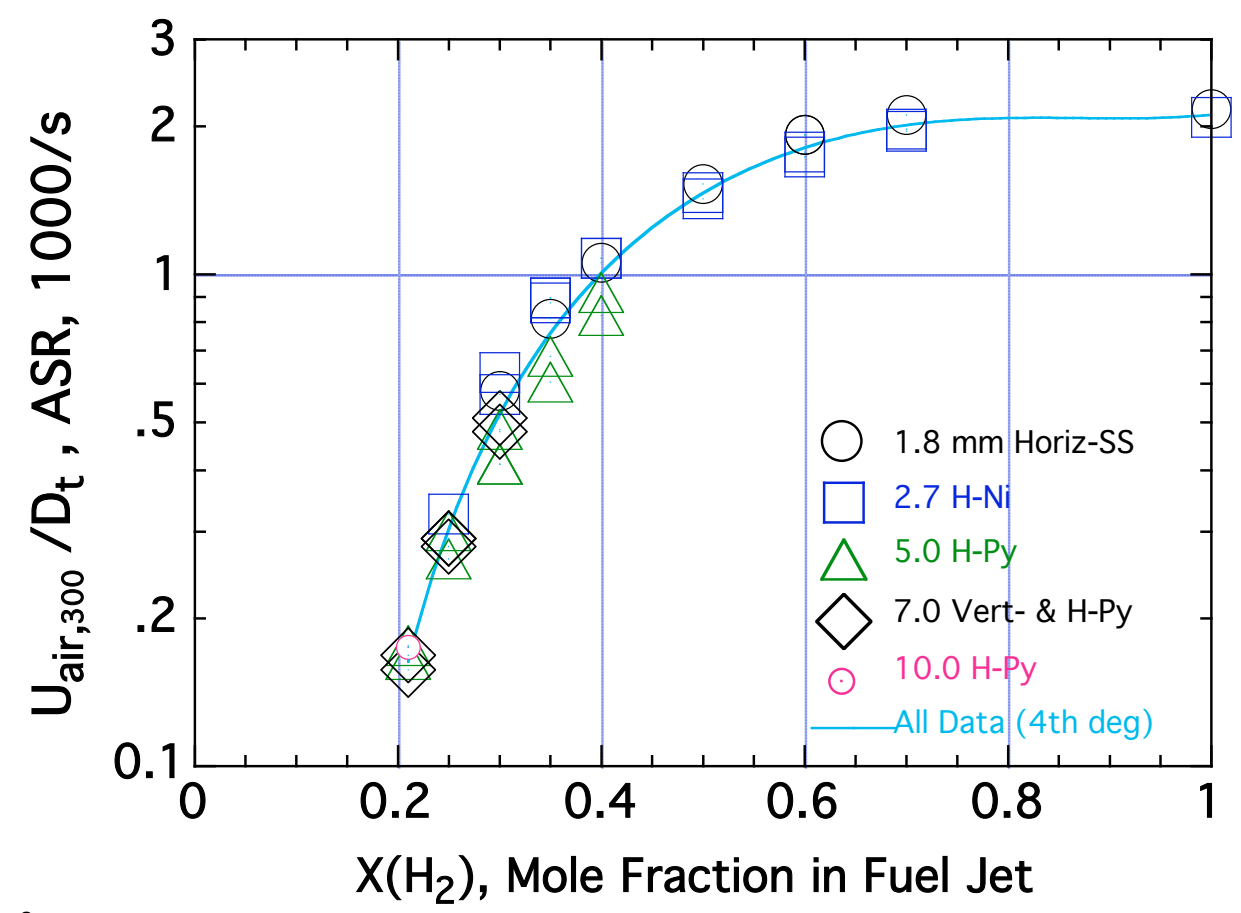

ig. 6

Fig. 6. Applied Stress Rates (ASR) for Tube-OJBs, at $300 \mathrm{~K}$ Airside Edge of Flame, for Extinction of $\mathrm{H}_{2} / \mathrm{N}_{2}-$ Air CFDFs.

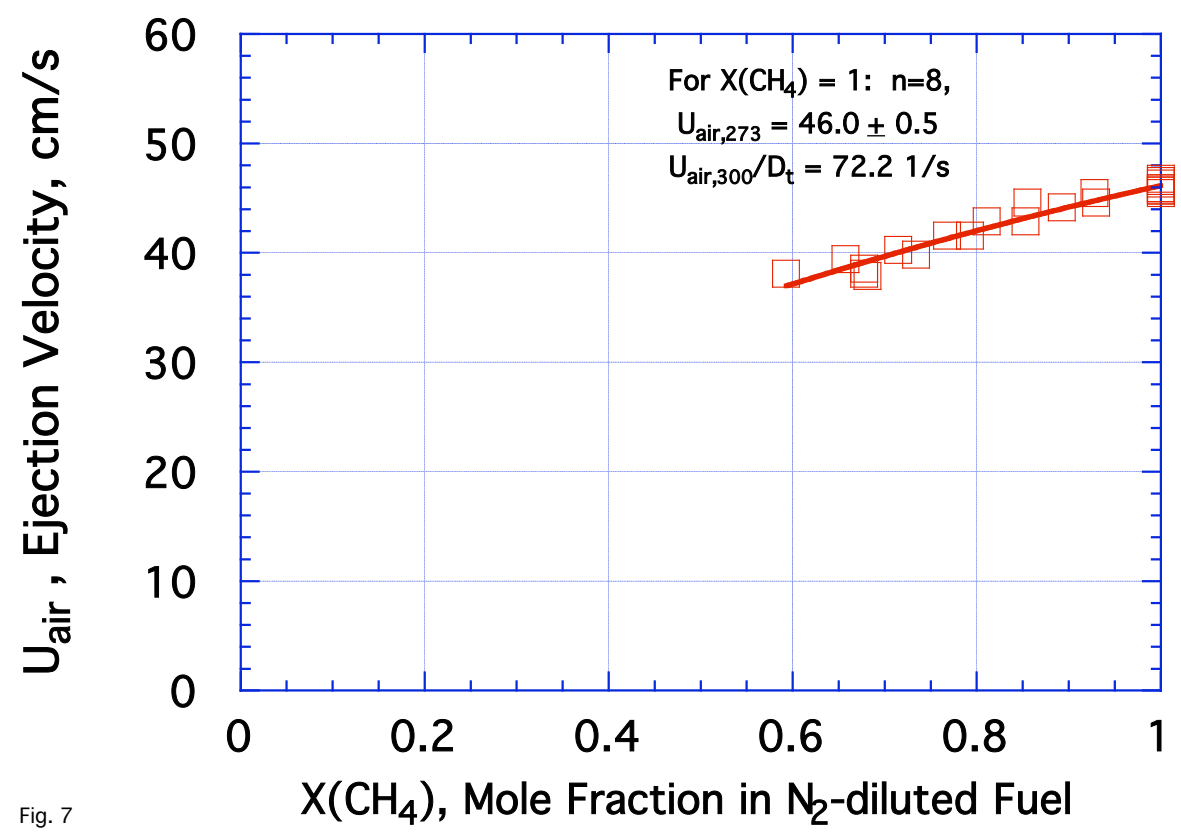

Fig. 7. Extinction of $\mathrm{CH}_{4} / \mathrm{N}_{2}$-Air CFDFs, using $7.0 \mathrm{~mm}$ VerticalTube-OJB (fuel on top). 


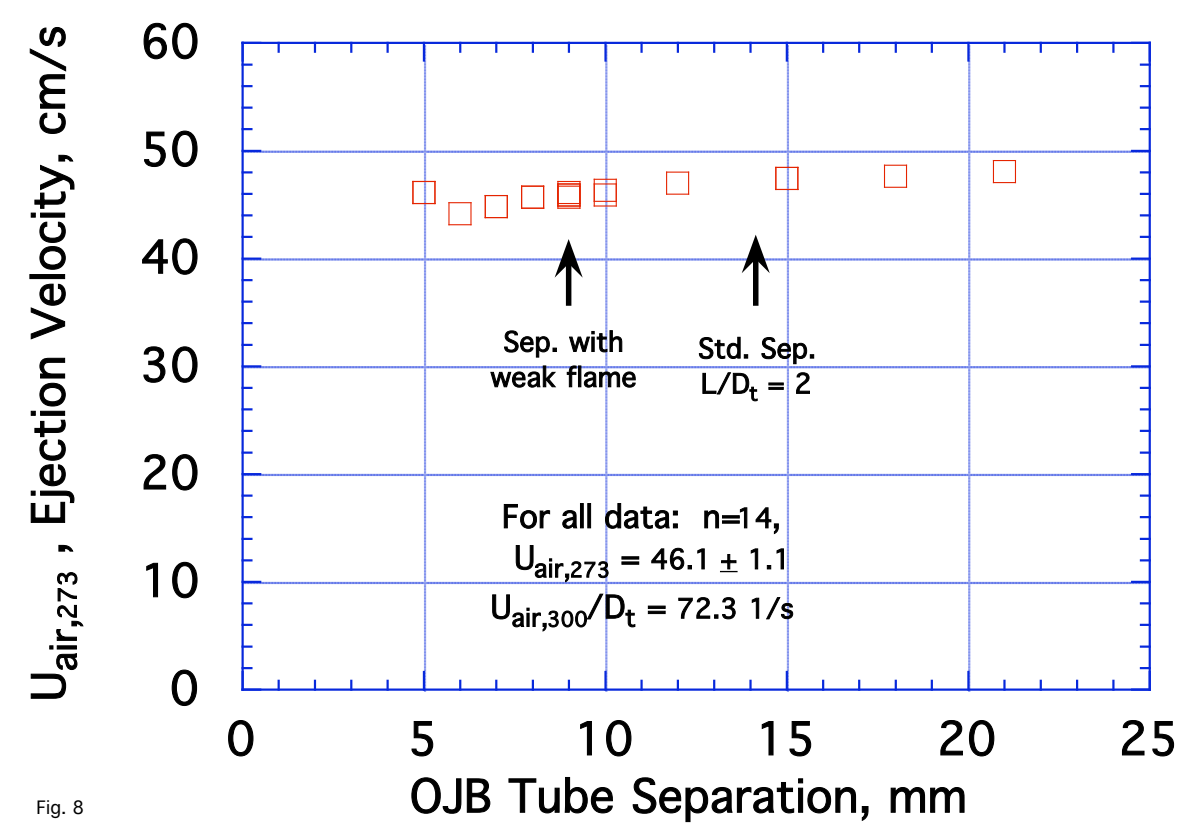

Fig. 8. Effect of Tube Separation on Extinction of $\mathrm{CH}_{4}$ vs. Air CFDFs, using $7.0 \mathrm{~mm}$ Horizontal-Tube-OJB.

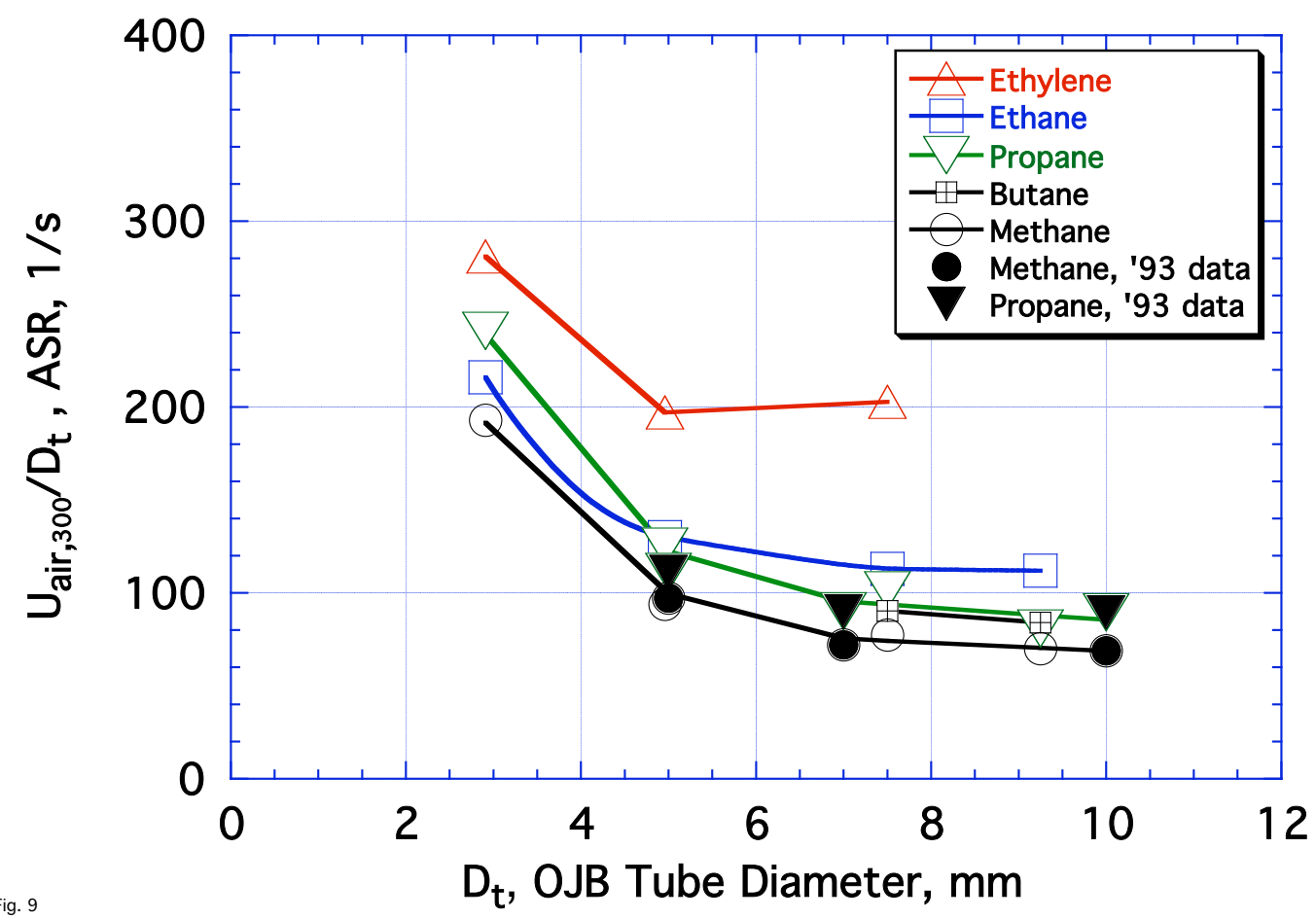

Fig. 9. Effect of OJB Tube Diameter on Applied Stress Rate at Extinction, for Various Gaseous Hydrocarbon vs Air CFDFs. 


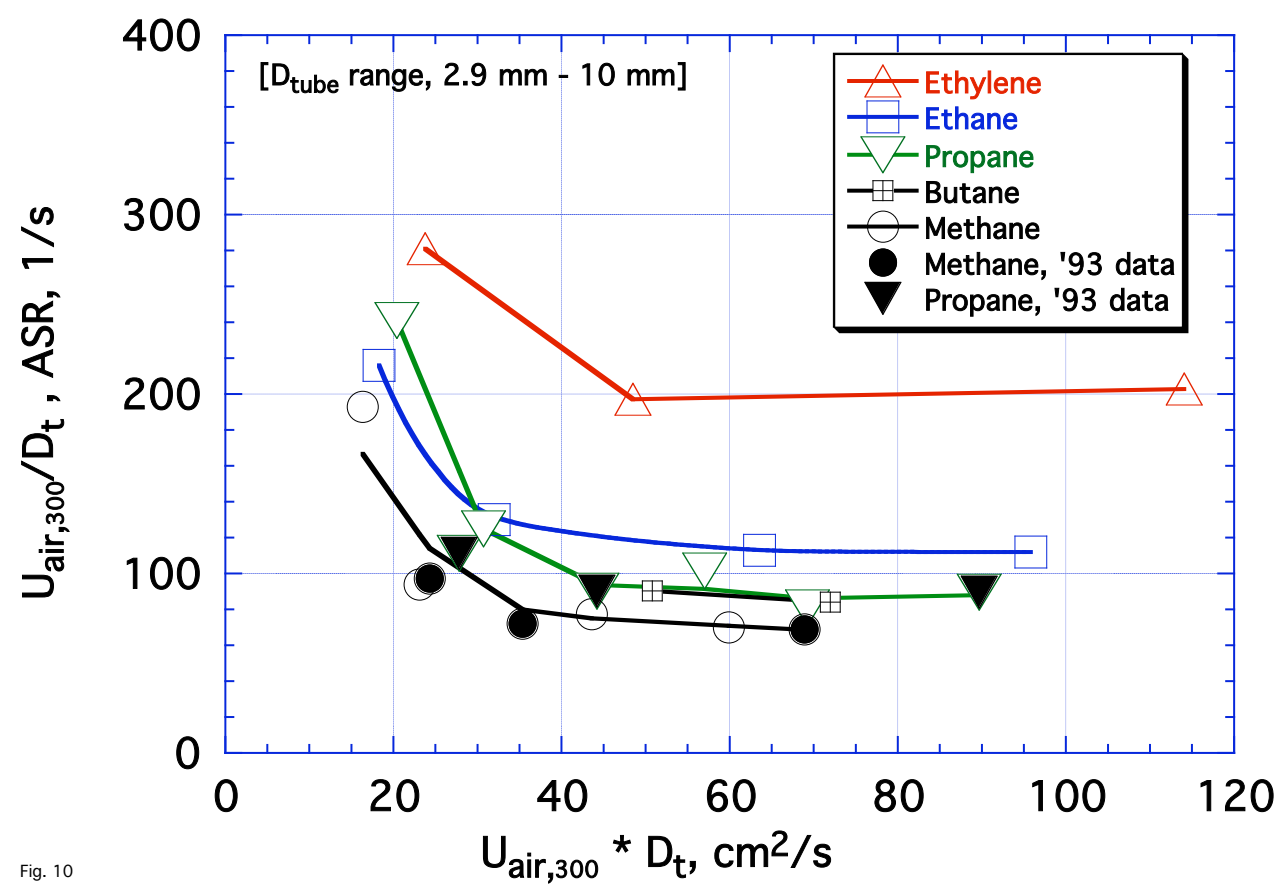

Fig. 10. Asymptotic Approach of Applied Stress Rates (ASRs) at Extinction, as Functions of Exit-Velocity * Tube-Diameter Product $(\sim R e)$ for Various Gaseous HC vs Air CFDFs.

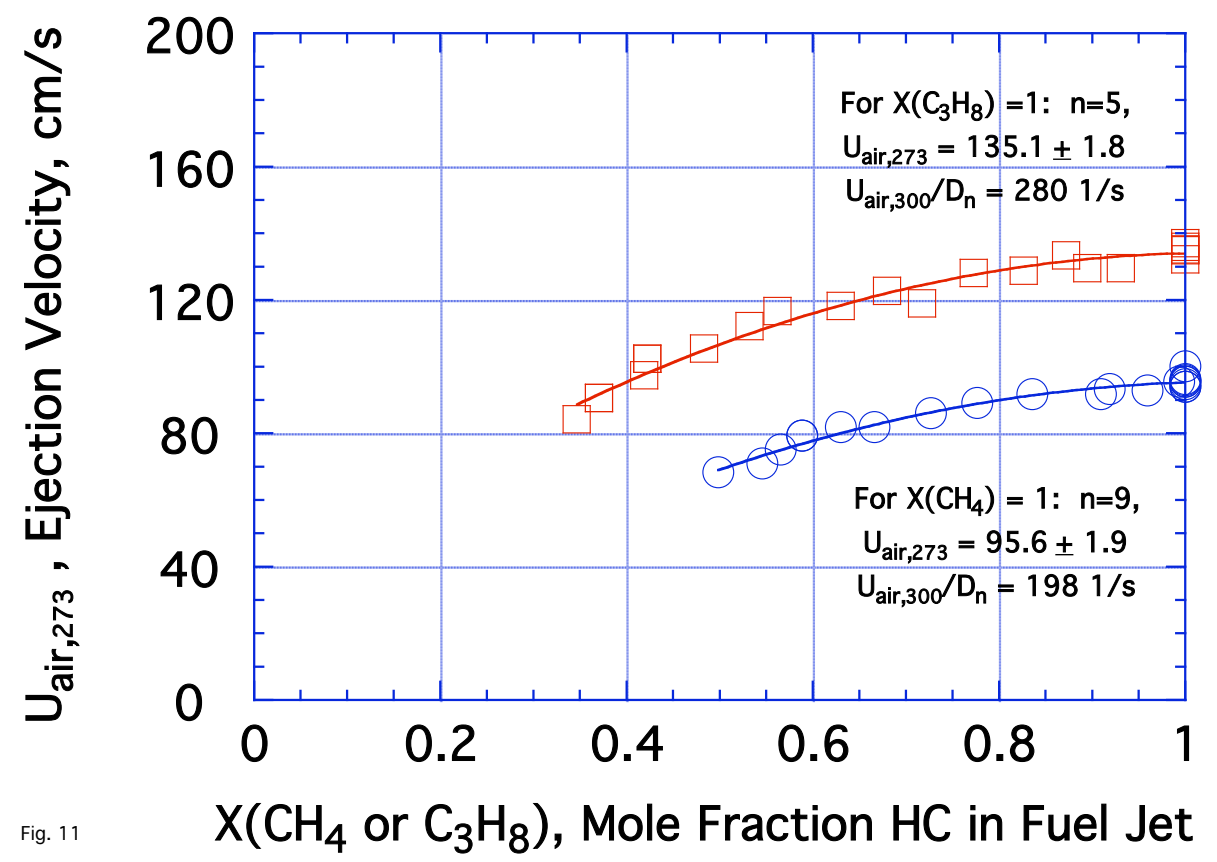

Fig. 11. Extinction of $\mathrm{CH}_{4} / \mathrm{N}_{2}$-Air and $\mathrm{C}_{3} \mathrm{H}_{8} / \mathrm{N}_{2}$-Air CFDFs, using 5.3 $\mathrm{mm}$ Brass Horizontal-Nozzle OJB. 


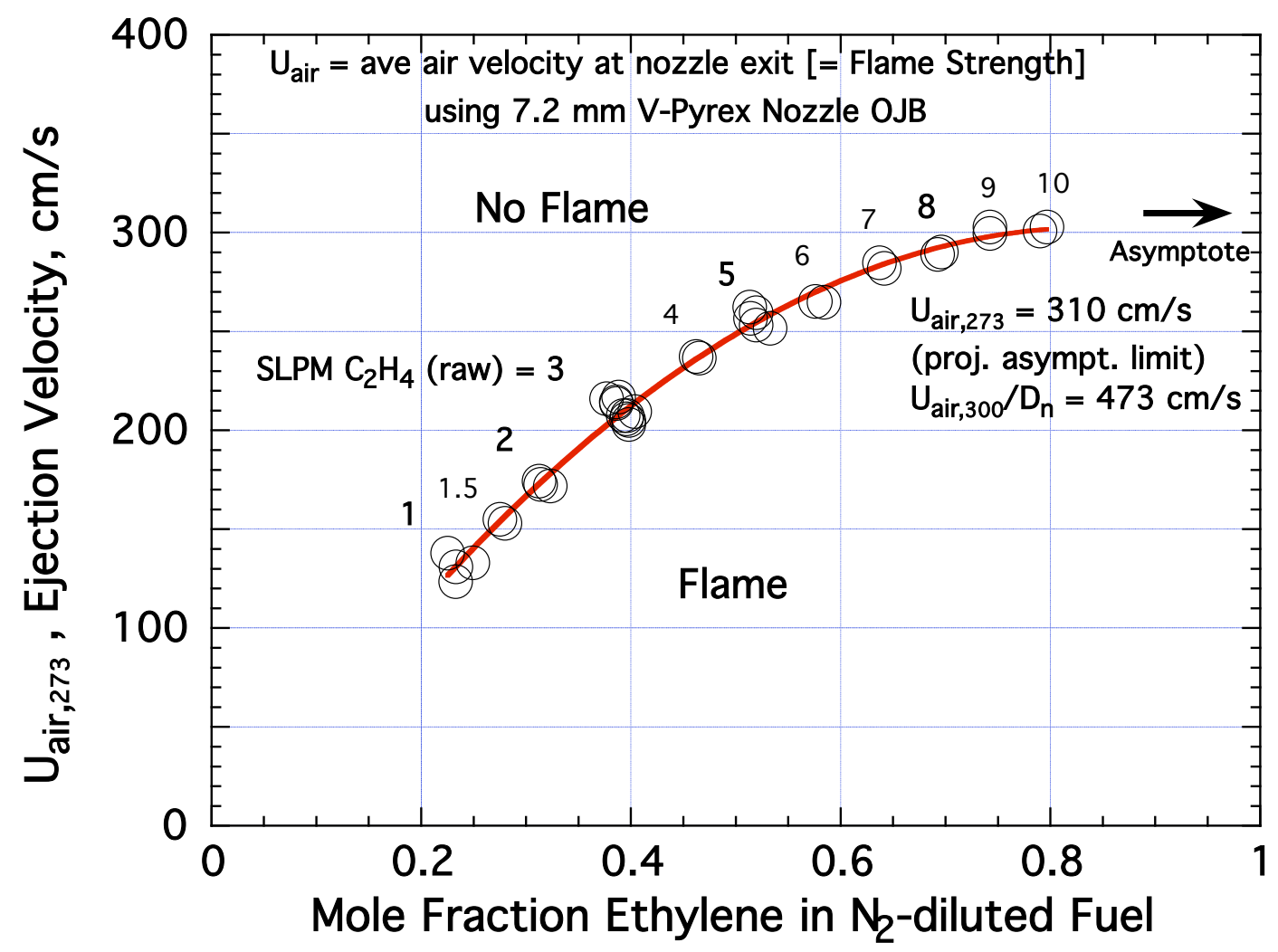

Fig. 12 Fig. 12. Steady-State Extinction of $\mathrm{C}_{2} \mathrm{H}_{4} / \mathrm{N}_{2}$-Air Counterflow Diffusion Flames, using $7.2 \mathrm{~mm}$ Vertical-Pyrex Nozzle OOJB. 


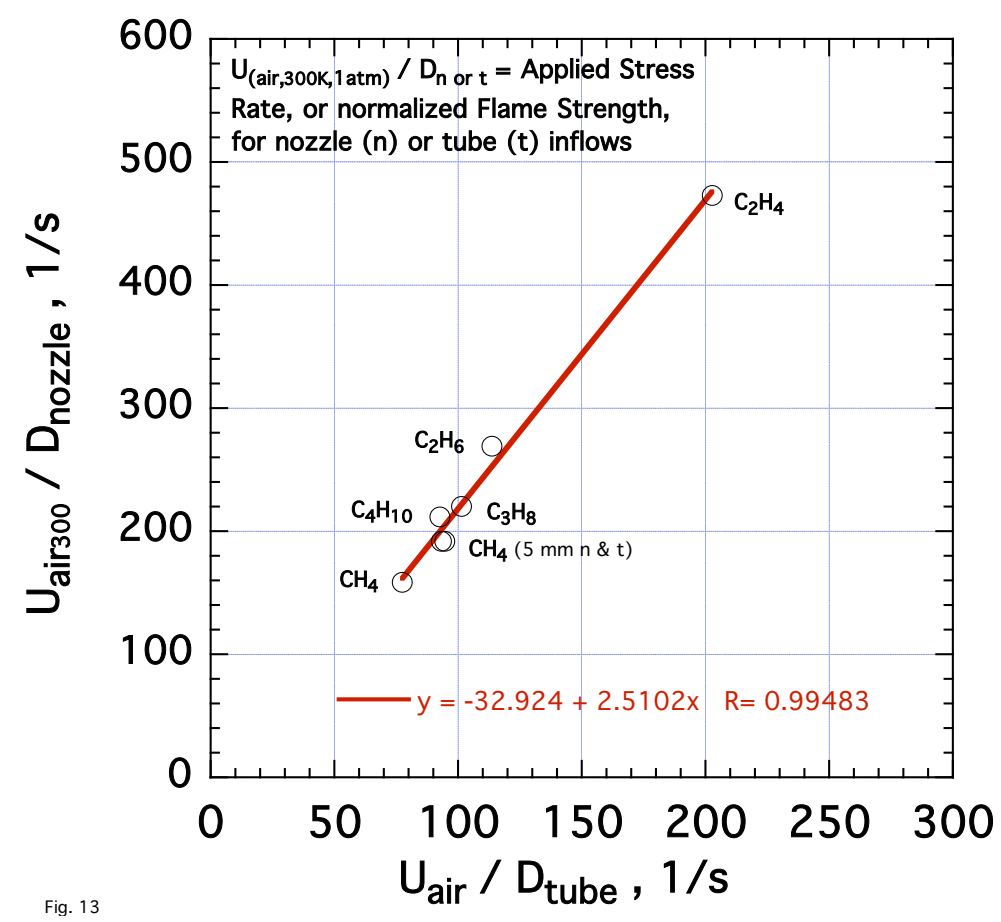

Fig. 13. OJB-Extinction-Limit "Idealized Flameholding Scale," from 7.2 $\mathrm{mm}$ Convergent Nozzle- and $7.5 \mathrm{~mm}$ Straight Tube-OJBs, for Methane, Propane, Butane, Ethane, and Ethylene-Air CFDFs.

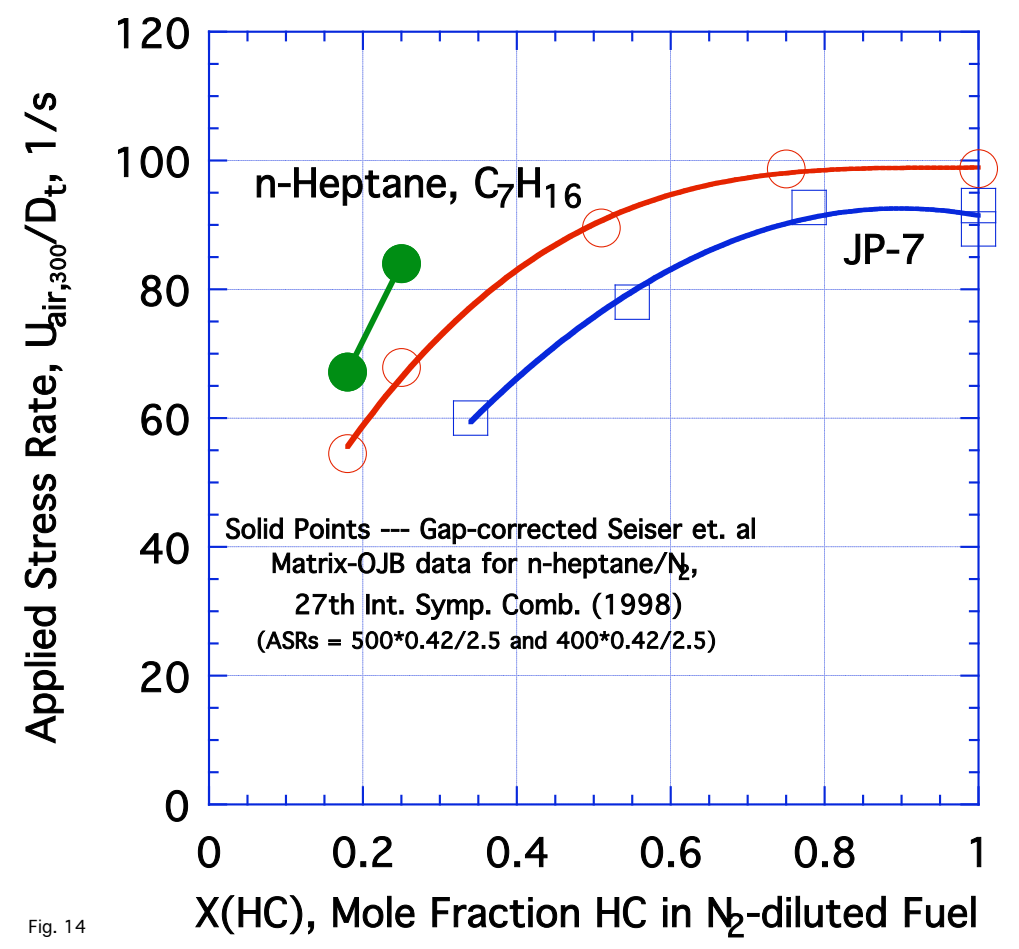

Fig. 14. Extinction of $n$-Heptane/ $/ \mathrm{N}_{2}-$ Air and JP-7/N 2 -Air CFDF's, using $7.5 \mathrm{~mm}$ Tube-OJB with Batch Vaporizer System; and comparison with Gap-Corrected Seiser et. al Heptane Data [36]. 


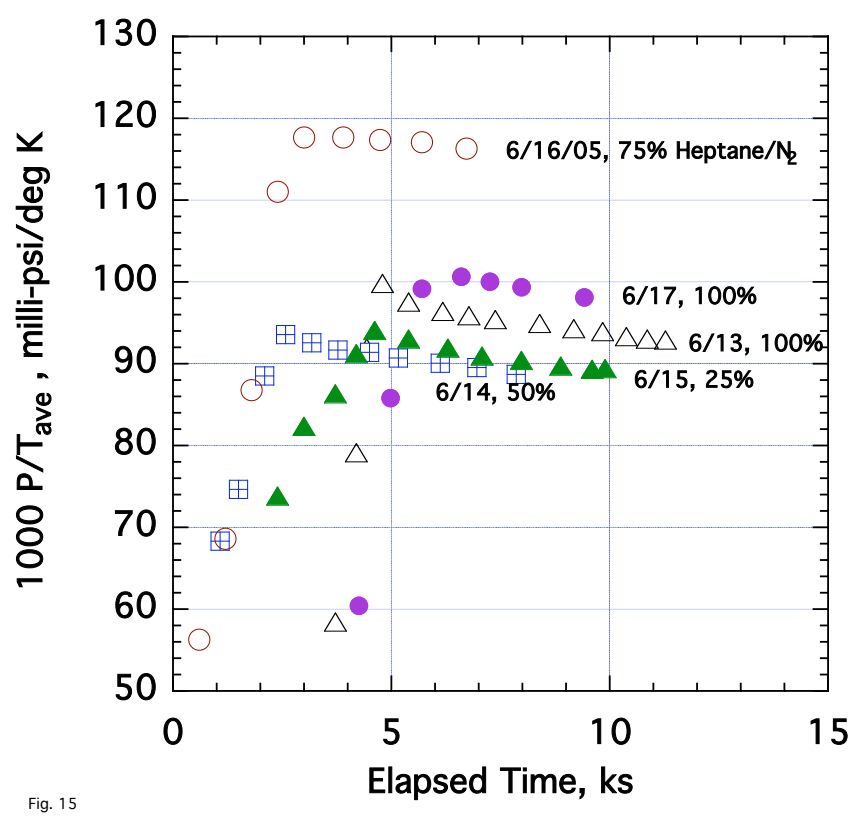

Fig. 15. Rise \& Decay of Pressure / Temperature Ratio ( $\sim$ moles fuel), for $n$-Heptane Vaporization in $N_{2}$, followed by a small leak (in a valve).

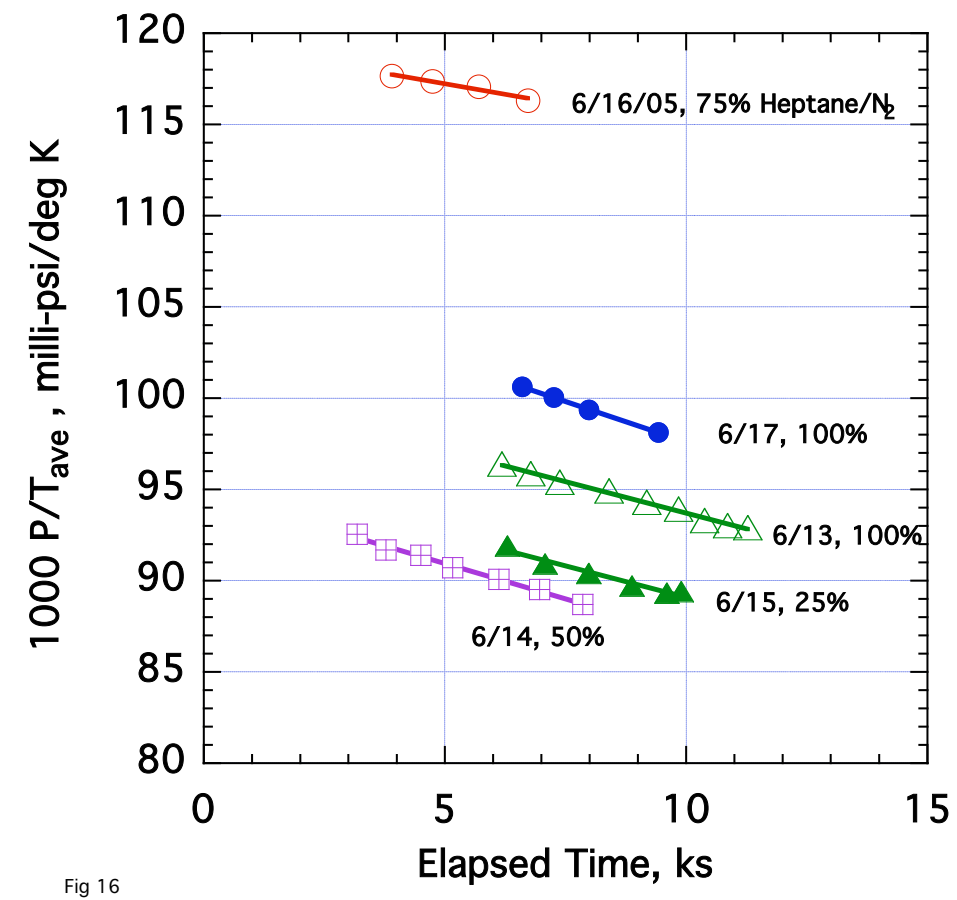

Fig. 16. Decay of Pressure / Temperature Ratio ( moles fuel), for $n$-Heptane Vaporization in $\mathrm{N}_{2}$, followed by a small leak (in a valve). 


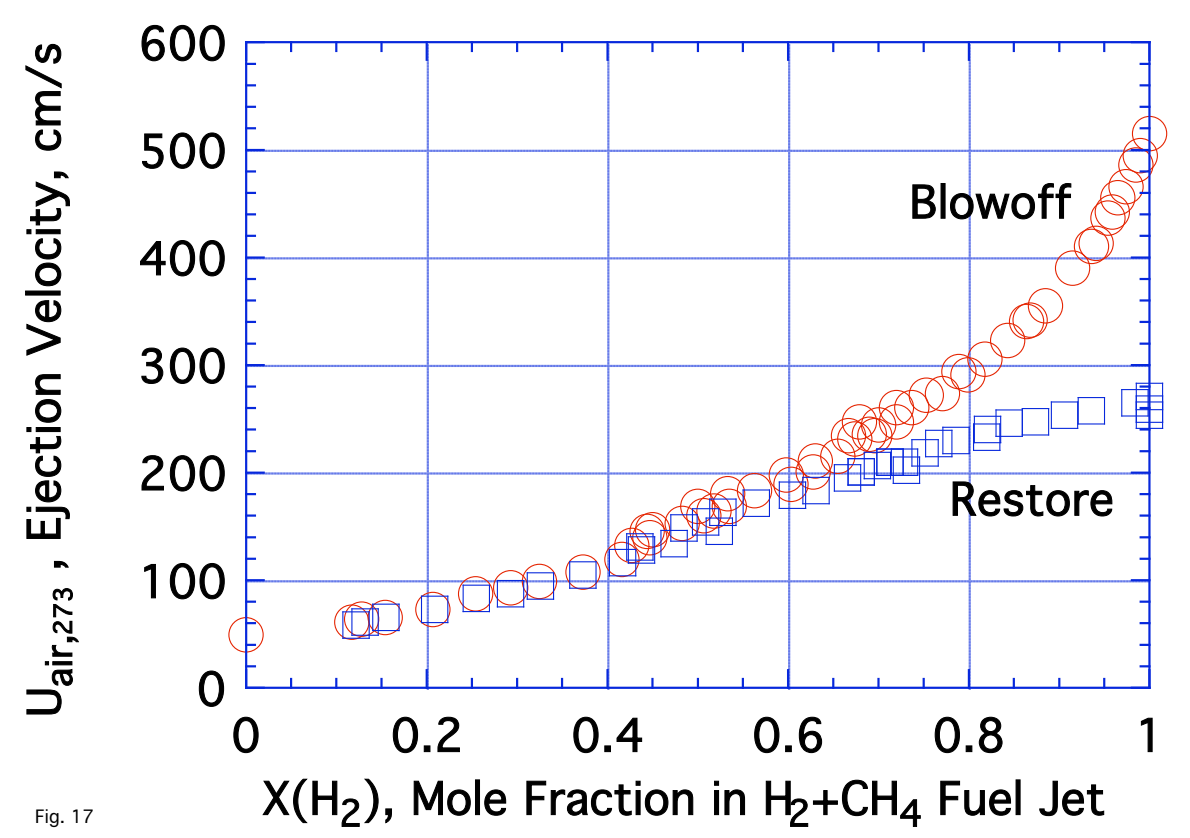

Fig. 17. Effect of Methane Reactivity (w/H-atom) on Extinction and Restoration of $\mathrm{CH}_{4}$-diluted $\mathrm{H}_{2}$ vs Air CFDFs, using $2.7 \mathrm{~mm}$ Tube-OJB.

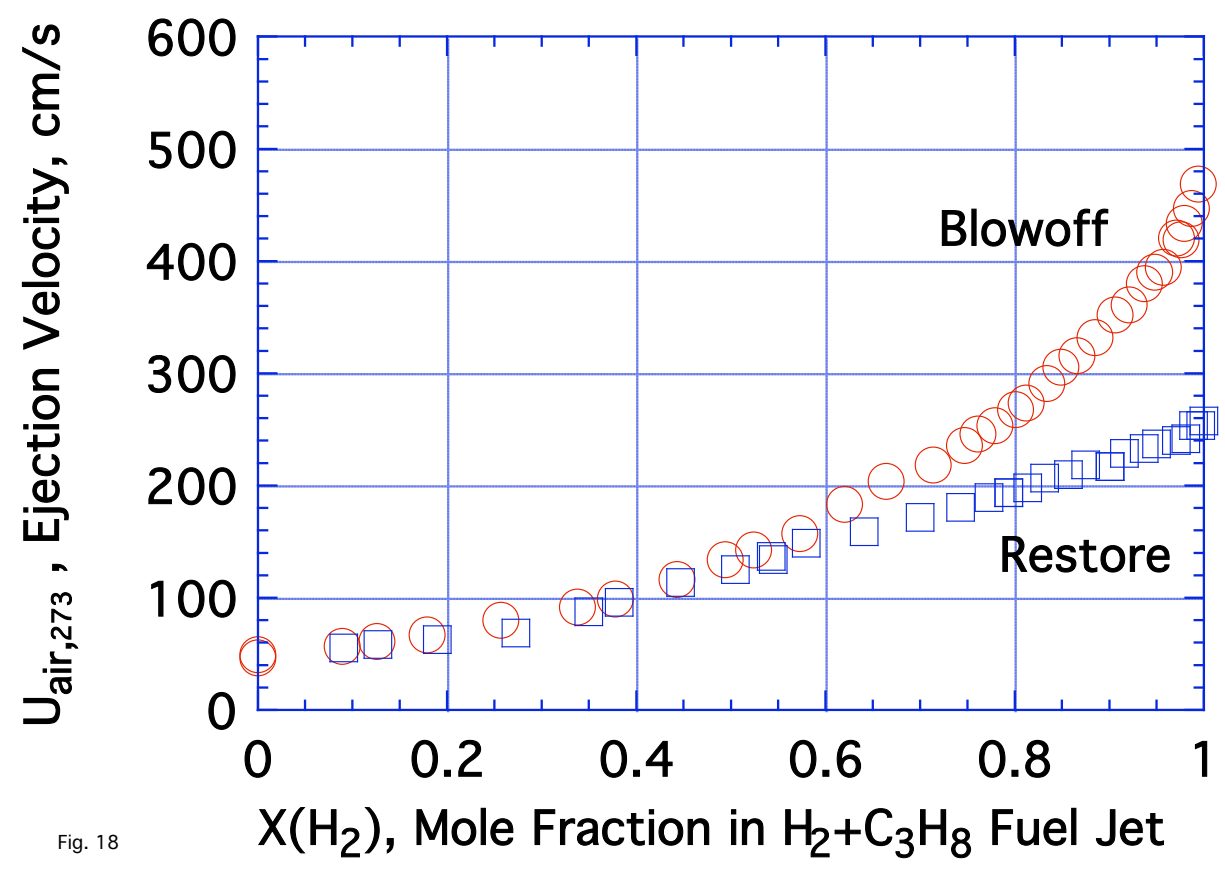

Fig. 18. Effect of Propane Reactivity (w/H-atom) on Extinction and Restoration of $\mathrm{C}_{3} \mathrm{H}_{8}$-diluted $\mathrm{H}_{2}$ vs Air CFDFs, using $2.7 \mathrm{~mm}$ Tube-OJB. 


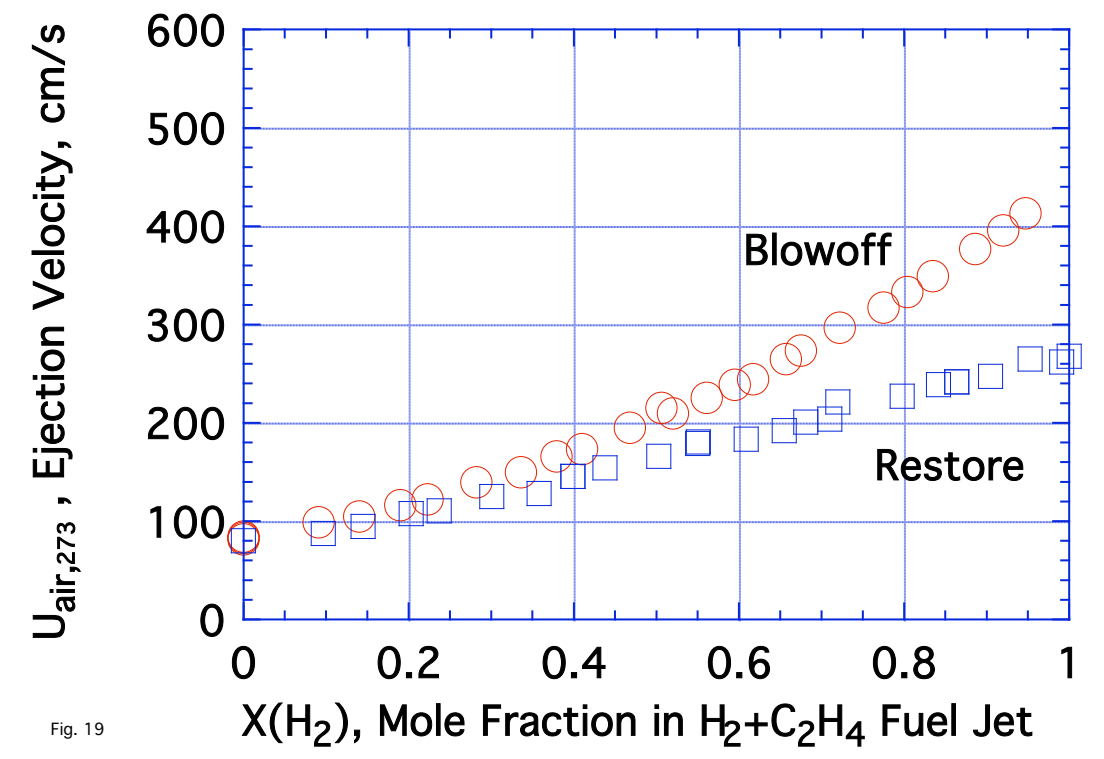

Fig. 19. Effect of Ethylene Reactivity (w/H-atom) on Extinction and Restoration of $\mathrm{C}_{2} \mathrm{H}_{4}$-diluted $\mathrm{H}_{2}$ vs Air CFDFs, using $2.7 \mathrm{~mm}$ Tube-OJB. 


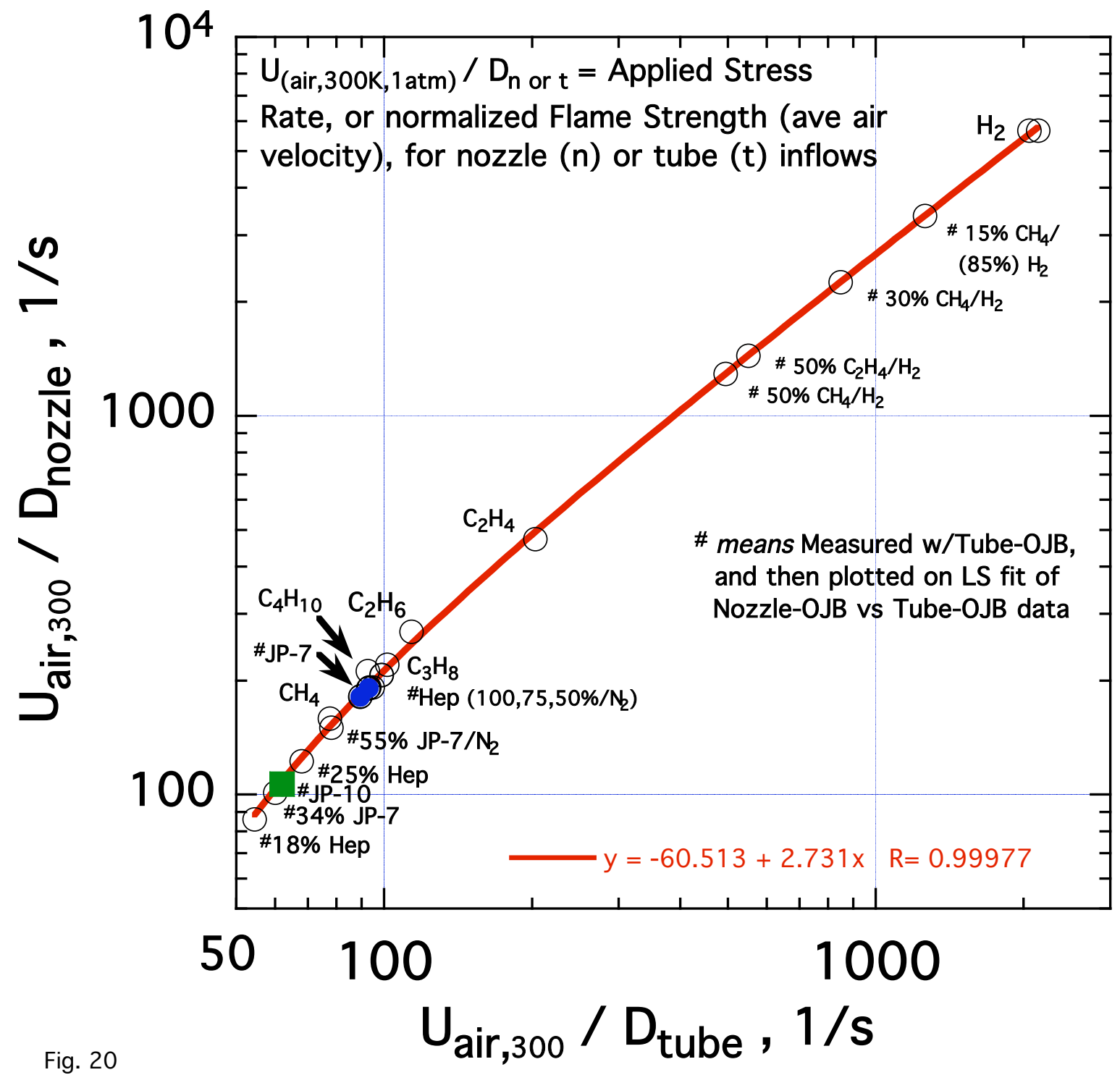

Fig. 20. OJB-Extinction-Limit "Idealized Flameholding Scale" from ConvergentNozzle- and Straight-Tube-OJBs, for JP-7, JP-10 and $n$-Heptane / Nitrogen; and Methane, Propane, Butane, Ethane, Ethylene, and Hydrogen-Air CFDFs. 


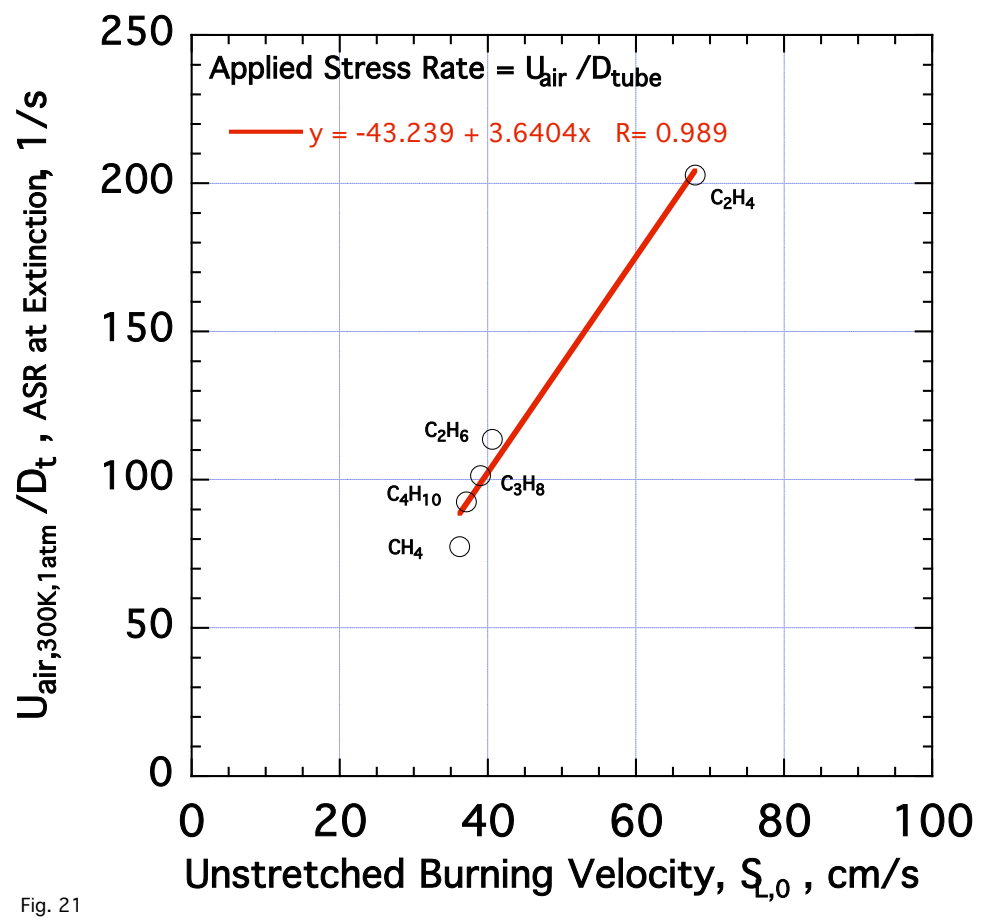

Fig. 21. Comparison of Extinction Limits, from $7.5 \mathrm{~mm}$ TubeOJB, with Unstretched Laminar Burning Velocity at phi $=1$, for Methane, Ethane, Propane, Butane and Ethylene-Air Flames.

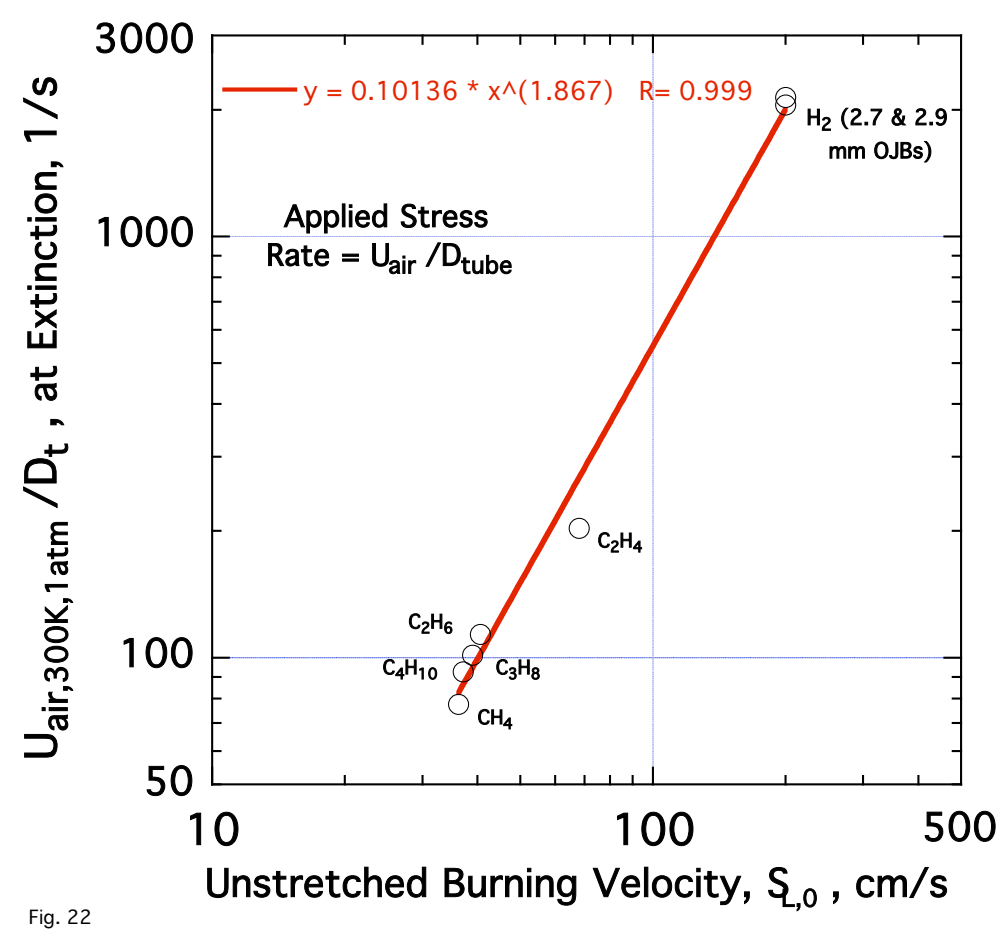

Fig. 22. Comparison of Extinction Limits, from $7.5 \mathrm{~mm}$ Tube-OJB, with Unstretched Laminar Burning Velocity at phi $=1$, for Methane, Ethane, Propane, Butane, Ethylene and $\mathrm{H}_{2}$-Air Flames. 